\title{
Quantum State-Resolved Studies of Chemisorption Reactions
}

\section{Helen Chadwick and Rainer D. Beck}

Laboratoire de Chimie Physique Moléculaire, École Polytechnique Fédérale de Lausanne, 1015 Lausanne, Switzerland; email: helen.chadwick@epfl.ch, rainer.beck@epfl.ch

Annu. Rev. Phys. Chem. 2017. 68:39-61

First published online as a Review in Advance on January 11, 2017

The Annual Review of Physical Chemistry is online at physchem.annualreviews.org

https://doi.org/10.1146/annurev-physchem052516-044910

Copyright (c) 2017 by Annual Reviews.

All rights reserved

\section{Keywords}

molecular beams, dissociative chemisorption, gas-surface reaction dynamics, mode specificity, bond selectivity, vibrational efficacy

\section{Abstract}

Chemical reactions at the gas-surface interface are ubiquitous in the chemical industry as well as in nature. Investigating these processes at a microscopic, quantum state-resolved level helps develop a predictive understanding of this important class of reactions. In this review, we present an overview of the field of quantum state-resolved gas-surface reactivity measurements that explore the role of the initial quantum state on the dissociative chemisorption of a gas-phase reactant incident on a solid surface. Using molecular beams and either quantum state-specific reactant preparation or product detection by laser excitation, these studies have observed mode specificity and bond selectivity as well as steric effects in chemisorption reactions, highlighting the nonstatistical and complex nature of gas-surface reaction dynamics. 


\section{BOA:}

Born-Oppenheimer approximation

PES: potential energy surface

DFT: density functional theory

\section{INTRODUCTION}

Chemical reactions of gas-phase molecules on solid surfaces are central to many industrial processes, including heterogeneous catalysis and chemical vapor deposition (1). Although on an industrial scale these processes appear to be complex, at a molecular level they can be decomposed into a series of elementary reaction steps. For example, in the steam reforming of methane to produce hydrogen, the rate-determining step is the dissociative chemisorption of methane on the catalyst surface (2). Steam reforming also involves the dissociative chemisorption of water and the desorption of the hydrogen formed by the reaction. An alternative method for producing hydrogen is the dry reforming of methane, which requires the dissociative chemisorption of both methane and carbon dioxide on the catalyst (3). The hydrogen made in these processes can then be used to synthesize ammonia in the Haber process, involving the dissociative chemisorption of both nitrogen and hydrogen (4). One of the steps necessary for the manufacture of semiconductor devices is the dissociation of silane on a silicon surface (5). Developing a predictive understanding of these and other elementary reactions is therefore not only of fundamental interest, but also of potentially great value to the associated industrial processes.

The dissociation of a polyatomic molecule on a solid surface, including all molecular and surface degrees of freedom, still presents a problem too complex to be treated by ab initio theory. To make the problem tractable, one must make certain approximations in theoretical modeling. For even the simplest systems involving multiple electrons, it is common to work within the Born-Oppenheimer approximation (BOA) (6). The BOA assumes that nuclei are stationary on the much faster timescale of electronic motion. Consequently, electronic and nuclear motion can be treated separately, allowing a potential energy surface (PES) to be obtained by calculating the energy of the molecule-surface system at different nuclear coordinates, which can then be used for modeling the dynamics. Scattering experiments for NO (7-9), CO (10-13), and $\mathrm{HCl}$ (14-16) from metal surfaces have provided evidence that the BOA is not always valid in these systems. The applicability of the BOA to gas-surface interactions is the subject of several recent reviews (17-19). Further approximations are often made in theoretical modeling of gas-surface reactions, including the use of density functional theory (DFT) (20) to describe electronic motion, as well as reduced-dimensional models (21) for treating nuclear motion either classically (22) or quantum mechanically (23).

To test the accuracy of the theoretical models and the approximations made at a molecular level, it is essential to have detailed experimental data where the variables controlling reactivity are systematically studied. The experiments described in this review fulfill this requirement by combining molecular beam techniques with quantum state-specific reactant preparation, or product detection, to measure state-resolved sticking coefficients, $S_{0}(v, J)$, defined as the probability that an incident reactant molecule prepared in a specific rovibrational quantum state with vibrational and rotational quantum numbers $v$ and $J$ reacts by dissociative chemisorption on a solid surface. Experiments investigating how translational energy and rovibrational quantum state influence the reactivity provide information about the PES and the transition-state structure. The relative efficiency with which vibrational energy in a particular vibrational mode, $v_{i}$, of the reactant promotes dissociative chemisorption compared to incident translational energy normal to the surface is quantified through the vibrational efficacy, $\eta\left(v_{i}\right)(24)$. The highest values of $\eta\left(v_{i}\right)$ are expected for vibrational modes that distort the reactant molecule toward the transition-state structure.

In addition to the translational energy and rovibrational quantum state of the incident molecule, the surface can also have a significant effect on the reactivity. The lack of a band gap for metals allows the excitation of electron-hole pairs at any energy, providing a pathway for vibrational relaxation of the incident molecule, in addition to phonon excitation, which can occur in any crystalline material. For semiconductors and insulators, the band gap between the valence and

Chadwick • Beck 
conduction bands is larger than the vibrational energy, preventing electron-hole pair excitation. Comparing results obtained for different surface materials can therefore serve to test the validity of the BOA. Changing between different crystallographic orientations of the same material can also have an effect on the sticking coefficient due to changes in packing symmetry, coordination number, and corrugation. Studying the dependence of the reactivity on the surface temperature shows how motion of the surface atoms, introducing increased corrugation, affects the barrier height of the reaction.

Our selection of gas-surface reactions that have been studied so far is motivated by a number of factors, such as experimental feasibility, relevance to applications, and amenability to theory. Several of the systems presented in this review have been the subject of previous reviews, and the interested reader is directed to the references given below. The outline of this review is as follows. We present an overview of the experimental methods employed for investigating stateresolved reactivity at the gas-surface interface in Section 2. In Section 3 we discuss studies on the dissociative chemisorption of methane on transition metal surfaces, which has become the prototype system for quantum state-resolved reactivity measurements (25-28). Section 3 is organized to highlight how different parameters affect the sticking coefficients of molecules. In Section 4, we present experiments for the dissociative chemisorption of $\mathrm{H}_{2}$ on copper (29-33), palladium (32), silver (32), and silicon $(34,35)$ surfaces, comparatively simple systems that have provided a testing ground for earlier theoretical work. We then discuss state-resolved measurements for other polyatomic-surface systems before finishing the review with a summary.

\section{EXPERIMENTAL METHODS}

In this section, we discuss the experimental techniques that have been used in the measurements included in this review. Detailed overviews of the state-of-the-art machines used to study reactions at the gas-surface interface are presented in References 36-39.

\subsection{Molecular Beams}

Molecular beams provide a high-density and collision-free source of incident reactant molecules with a well-defined and narrow range of velocities (40). Their use allows control of both the incident speed and the angle, making them ideal tools for studying gas-surface reactions (41, 42). As vibrational cooling is inefficient in the supersonic expansion used to generate a molecular beam, changes in nozzle temperature control the population of the vibrational states of molecules in the beam, allowing the effect of the thermally populated vibrations to be determined. The use of molecular beams for surface dynamics experiments has demonstrated the dramatic increase in reactivity caused by increasing either the incident translational energy or the vibrational energy of the reactant molecules (43-48).

\subsection{Reactant Preparation by Laser Excitation}

Lasers enable the state-specific preparation of incident reactant molecules as well as the stateresolved detection of molecules scattered from a solid surface (49). State preparation by laser excitation removes the averaging over vibrational and rotational states inherent in experiments with thermal beams. The quantum state distribution of scattered or desorbing molecules can be obtained by resonantly enhanced multiphoton ionization (REMPI), although bolometric detection in combination with laser tagging has also been used (50).

State-specific excitation of the incident reactant molecules provides a direct method for investigating the effect of the initial rovibrational state on the dissociative chemisorption. Utz and
REMPI: resonantly enhanced multiphoton ionization 
RAP: rapid adiabatic passage

AES: Auger electron spectroscopy coworkers (26) have shown that the state-resolved reactivity $S_{0}\left(v_{i}\right)$ can be obtained from the measured average reactivities with laser excitation $\left[S_{0}\right.$ (laser on) $]$ and without laser excitation $\left[S_{0}\right.$ (laser off)] as

$$
S_{0}\left(v_{i}\right)=\frac{S_{0}(\text { laser on })-S_{0}(\text { laser off })}{f_{\text {exc }}}+S_{0}(v=0),
$$

where $f_{\text {exc }}$ is the fraction of the incident molecules that are transferred from the ground state $v=0$ to the excited rovibrational state by the laser. A distinction is made between the laser-off reactivity and the vibrational ground-state reactivity, $S_{0}(v=0)$, as thermally populated vibrations can make a significant contribution to the laser-off sticking coefficient, especially at higher nozzle temperatures. For this reason, $S_{0}(v=0)$ can be difficult to determine experimentally, although it is often orders of magnitude smaller than $S_{0}\left(v_{i}\right)$, allowing this term to be neglected without introducing significant error.

To accurately determine $S_{0}\left(v_{i}\right)$, it is necessary to excite a significant fraction of the incident reactant molecules to a specific rovibrationally excited state. Coherent excitation by resonant infrared laser radiation will cause Rabi cycling of the population between the levels that are connected by an electric dipole transition, allowing population transfer from an initial to a final rovibrational state. When using Rabi cycling, however, it is difficult to control the final state population. Because the Rabi frequency depends on the laser intensity and the transition dipole moment, not all molecules in the molecular beam will have the same cycling time due to intensity variation in the laser beam profile, the presence of degenerate $M$ levels with different transition moments, and the distribution of velocities. When averaged over a sufficiently large number of Rabi frequencies and cycles, half of the initial state population will be transferred to the excited rovibrational level.

Through application of a time-dependent laser frequency (a chirp), it is possible to achieve complete population transfer from an initial to a final rovibrational state via rapid adiabatic passage (RAP) (51). RAP is more efficient and more robust for quantum state-specific reactant preparation than is Rabi cycling, as it is less dependent on the excitation field intensity, the Rabi frequency, and both the velocity distribution and the angular divergence of the molecular beam. For RAP to occur, the continuous-wave laser beam is focused by a cylindrical lens to create curved wavefronts in the excitation field. This wavefront curvature will create a Doppler tuning seen by the reactant molecules as they traverse the laser beam, which can be adjusted to result in complete transfer of the population from the initial to the final state. Using two consecutive RAP excitation steps allows the preparation of overtone and combination bands and provides access to totally symmetric vibrational states that cannot be accessed via a one-photon transition from the ground state (52). An alternative method of preparing totally symmetric vibrational modes, which has been used to prepare the symmetric stretch of $\mathrm{CH}_{4}$, is stimulated Raman pumping (53). Stimulated emission pumping (54) has also been employed to prepare molecules in higher vibrational states.

\subsection{Product Detection}

A widely applicable and commonly used method for detecting surface-bound adsorbates on a conducting surface is Auger electron spectroscopy (AES) (55). For AES detection, the surface is moved in front of an electron energy analyzer and bombarded with a primary beam of fast electrons with 3-5 keV of kinetic energy. Inelastically scattered Auger electrons are filtered by the electron energy analyzer and detected according to their kinetic energy, which allows the analysis of the elemental composition of the surface. AES can neither detect hydrogen or helium nor distinguish 
between isotopes of the same element. To overcome these limitations, alternative techniques have been developed.

One method is to titrate the adsorbed species using a chemical reaction to produce gas-phase species that can be detected by mass spectrometry. Johnson et al. (56) showed that methyl species, $\mathrm{CH}_{3}$ (ads), chemisorbed on a $\mathrm{Ni}(111)$ surface, recombine only with subsurface hydrogen atoms when the sample temperature is increased, whereas surface hydrogen atoms do not recombine with $\mathrm{CH}_{3}$ (ads). The desorbing $\mathrm{CH}_{4}$ is detected by a mass spectrometer to quantify the $\mathrm{CH}_{3}$ (ads) coverage resulting from a deposition experiment. This method has the advantages of being selective for $\mathrm{CH}_{3}$ (ads) and highly sensitive. Bulk hydrogen titration cannot be used on platinum surfaces, because as the surface temperature $\left(T_{\mathrm{s}}\right)$ increases, both recombinative desorption of $\mathrm{CH}_{3}(\mathrm{ads})$ to make $\mathrm{CH}_{4}$ and dehydrogenation of the $\mathrm{CH}_{3}$ (ads) to make surface-bound $\mathrm{C}(\mathrm{ads})$ occur $(57,58)$. The branching ratio of these two pathways is sensitive to the amounts of both $\mathrm{CH}_{3}$ (ads) and $\mathrm{H}(\mathrm{ads})$ on the surface (58), preventing an accurate calibration of the method.

Surface-bound carbon can also be detected through oxygen titration (46) by exposing the adsorbate-covered surface to a beam of oxygen. The oxidation products $\mathrm{CO}$ and $\mathrm{CO}_{2}$ promptly desorb and are detected by mass spectrometry.

For the state-resolved reactivity measurements of $\mathrm{SiH}_{4}$ dissociation on $\mathrm{Si}(100)$, the adsorbed hydrogen can be detected by secondary ion mass spectrometry (SIMS) (59). Following the deposition of $\mathrm{SiH}_{4}$, the silicon surface is oxidized, which increases the yield of $\mathrm{Si}^{+}$ions detected. The reactivity of the silicon surface to oxygen is reduced by 12 orders of magnitude where adsorbed hydrogen coming from the dissociation of $\mathrm{SiH}_{4}$ passivates the surface (60), effectively reducing the yield of $\mathrm{Si}^{+}$ions detected. Monitoring the current from $\mathrm{Si}^{+}$allows the coverage of hydrogen on the surface to be determined.

The detection methods discussed so far are invasive in the sense that they can be used to quantify surface-bound adsorbates only after a deposition experiment. A noninvasive method that can be employed to monitor the adsorbate uptake throughout the reactant deposition is reflection absorption infrared spectroscopy (RAIRS) (61), as the weak infrared light perturbs neither the incident molecules nor the adsorbates. This has been used for detecting $\mathrm{CH}_{3}$ (ads) on $\mathrm{Pt}(111)$, as well as its deuterated isotopologues, which can be distinguished due to isotopic shifts of the adsorbate vibrational frequencies. However, the use of RAIRS is limited to surface temperatures where the nascent chemisorption products are stable and do not desorb.

The final method used in the experiments included in this review is to probe the scattered or desorbing molecules by REMPI. Species such as $\mathrm{H}_{2}, \mathrm{~N}_{2}, \mathrm{NO}$, and $\mathrm{HCl}$, which all possess long-lived excited electronic states, can be detected by REMPI with quantum state resolution and with very high sensitivity. Using time-of-flight (TOF) methods in combination with REMPI, one can obtain both the rovibrational state and the translational energy of the scattered molecules. For desorbing molecules, detailed balance can be used to infer information about the dissociative chemisorption, and when scattered molecules are probed, the number of molecules that stick can be found from the difference between the incident flux and the scattered flux.

\section{DISSOCIATIVE CHEMISORPTION OF METHANE ON TRANSITION METAL SURFACES}

\subsection{Mode Specificity}

The earliest quantum state-resolved studies of methane chemisorption focused on comparing the effects of vibrational energy $\left(E_{\mathrm{v}}\right)$ and translational energy $\left(E_{\mathrm{t}}\right)$ on the sticking coefficient. Juurlink et al. (62) measured $S_{0}\left(v_{3}\right)$ for $\mathrm{CH}_{4}$ dissociation on $\mathrm{Ni}(100)$ as a function of $E_{\mathrm{t}}$ and compared
$T_{\mathrm{s}}$ : surface temperature

RAIRS: reflection absorption infrared spectroscopy

TOF: time of flight

$E_{\mathrm{v}}$ : vibrational energy

$E_{\mathrm{t}}$ : translational energy 
IVR: intramolecular vibrational energy redistribution it to the reactivity $S_{0}$ (laser off), which is an upper limit for the ground-state reactivity $S_{0}(v=$ $0)$. Similarly, Higgins et al. (63) and Schmid et al. (64) determined $S_{0}\left(2 v_{3}\right)$ for the dissociation of methane on $\mathrm{Pt}(111)$ and on $\mathrm{Ni}(100)$, respectively. In each case, it was observed that adding either $E_{\mathrm{t}}$ or $E_{\mathrm{v}}$ to the incident methane increased the sticking coefficient, but that each promoted the reaction to a different extent. These measurements provided the first indication that methane chemisorption is not statistical; i.e., its reactivity does not simply depend on the total energy of the reactant molecule but on how the energy is distributed over its different molecular degrees of freedom.

The nonstatistical and mode-specific nature of methane chemisorption was clearly demonstrated by the results reported by Beck et al. (65), who showed that excitation of two different isoenergetic vibrational modes of $\mathrm{CD}_{2} \mathrm{H}_{2}$ leads to significantly different sticking coefficients on $\mathrm{Ni}(100)$. The authors determined the state-resolved reactivity of $\mathrm{CD}_{2} \mathrm{H}_{2}$ for the vibrational states labeled $v_{1}+v_{6}$ and $2 v_{6}$ in a normal mode basis. In a local mode basis, the $v_{1}+v_{6}$ state corresponds to the excitation of a single $\mathrm{C}-\mathrm{H}$ bond with two quanta of $\mathrm{C}-\mathrm{H}$ stretch $(|2000\rangle)$ and the $2 v_{6}$ state to the excitation of one quantum of $\mathrm{C}-\mathrm{H}$ stretch in each of the two $\mathrm{C}-\mathrm{H}$ bonds $(|1100\rangle)$. The reactivity for the $|2000\rangle$ state was measured to be up to a factor of five higher than that for the |1100) state, consistent with the idea that in order to break a single $\mathrm{C}-\mathrm{H}$ bond in $\mathrm{CD}_{2} \mathrm{H}_{2}$, it is more efficient to localize all the $\mathrm{C}-\mathrm{H}$ stretch amplitude in a single $\mathrm{C}-\mathrm{H}$ bond than to stretch both $\mathrm{C}-\mathrm{H}$ bonds to a lesser extent.

This first example of mode specificity was followed by the experimental study of different vibrational modes of $\mathrm{CH}_{4}$ on a range of transition metal surfaces, including $v_{1}+v_{4}, v_{3}+v_{4}, 2 v_{3}$, and $2 v_{2}+v_{4}$ on $\mathrm{Pt}(110)-(1 \times 2)(66) ; 2 v_{3}(67), 3 v_{4}(68), v_{3}(69)$, and $v_{2}+v_{4}$ (70) on Ni(111); $3 v_{4}$ (68), $v_{3}(62), v_{1}(53,71)$, and $2 v_{3}(64)$ on $\mathrm{Ni}(100) ; v_{3}(72)$ and $2 v_{3}(52,67,73)$ on $\mathrm{Pt}(111)$; and $v_{3}$ on $\operatorname{Ir}(111)$ (74). Comparison of these studies shows that the vibrational efficacy of the symmetric stretch $\left(v_{1}\right)$ is the largest, followed by that of the antisymmetric stretch $\left(v_{3}\right)$, and that the efficacies of the bends $\left(v_{2}\right.$ and $\left.v_{4}\right)$ are similar and smallest. Furthermore, the measurements on $\operatorname{Pt}(110)-(1 \times 2)$ show that the efficacy of stretch-bend combinations $\left(v_{1}+v_{4}\right.$ and $\left.v_{3}+v_{4}\right)$ is larger than those for the pure stretch $\left(2 v_{3}\right)$ or pure bend $\left(2 v_{2}+v_{4}\right)$ states, demonstrating that the efficacies of the overtones and combination bands cannot simply be calculated from those of the contributing fundamental vibrational modes. As an example, the state-resolved $\mathrm{CH}_{4}$ sticking coefficients on $\mathrm{Pt}(110)-(1 \times 2)$ are shown in Figure 1.

In a recent study using double resonance excitation by RAP, Hundt et al. (52) measured different efficacies for the three different symmetry components of the $2 v_{3}$ overtone for $\mathrm{CH}_{4}$ dissociation on $\mathrm{Pt}(111)$. The authors attributed the observed mode specificity to different degrees of $\mathrm{C}-\mathrm{H}$ stretch vibrational amplitude localization in the dissociating bond (75). All these results demonstrate that the intramolecular vibrational energy redistribution (IVR) in the reactant molecule is slow on the several-hundred-femtosecond timescale of the reactive collision (76), in contradiction with the basic assumption of fast and complete IVR made by statistical rate theories (77-80).

\subsection{Controlling Dissociation Through Vibrational Excitation}

Killelea et al. (81) were the first to demonstrate vibrational bond selectivity in the dissociative chemisorption of methane on $\mathrm{Ni}(111)$. They showed that excitation of the $\mathrm{C}-\mathrm{H}$ stretch fundamental $v_{1}$ in $\mathrm{CHD}_{3}$ results in a $\mathrm{C}-\mathrm{H}: \mathrm{C}-\mathrm{D}$ cleavage branching ratio greater than 30:1. This is in contrast to measurements made without laser excitation, where a statistical branching ratio of 1:3 was observed. To detect and distinguish the adsorbed methyl species, Killelea et al. used deuterium titration, where subsurface $\mathrm{D}$ atoms recombine with the $\mathrm{CHD}_{2}(\mathrm{ads})$ and $\mathrm{CD}_{3}(\mathrm{ads})$ on 


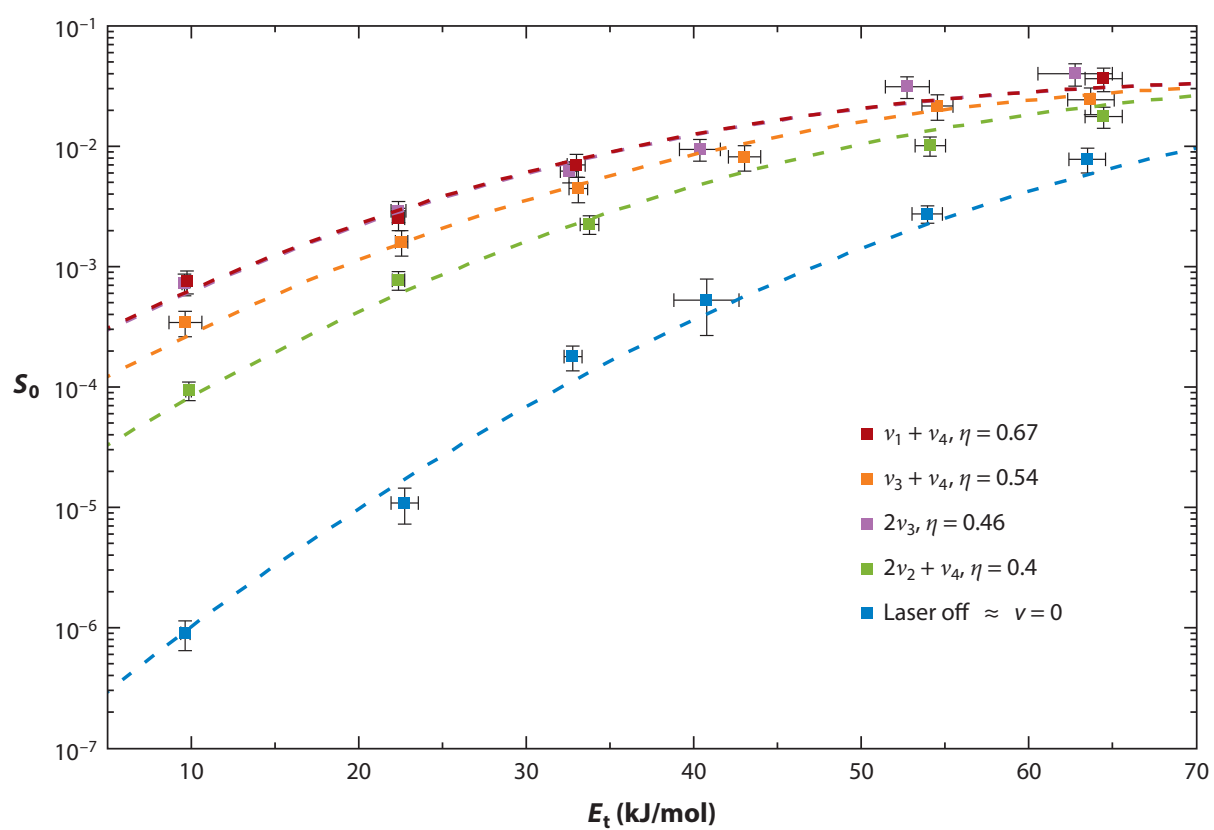

Figure 1

State-resolved sticking coefficients of $\mathrm{CH}_{4}$ on $\mathrm{Pt}(110)-(1 \times 2)$ at $T_{\mathrm{s}}=400 \mathrm{~K}$. Fitting of S-shaped reactivity curves (24) is used to extract $\eta\left(v_{i}\right)$ for the four vibrationally excited states. Figure adapted from Reference 66.

the $\mathrm{Ni}(111)$ surface as $T_{\mathrm{s}}$ is increased. The desorbing $\mathrm{CHD}_{3}$ and $\mathrm{CD}_{4}$ are detected by a mass spectrometer. The subsurface $\mathrm{D}$ atom titration method is limited to studying bond selectivity in $\mathrm{CHD}_{3}$ on $\mathrm{Ni}(111)$. Using RAIRS detection, Chen et al. (82) extended the bond selectivity studies to all the partially deuterated isotopologues of methane on $\mathrm{Pt}(111)$. The RAIR spectra in Figure 2 show that excitation of a $\mathrm{C}-\mathrm{H}$ stretch fundamental leads exclusively to $\mathrm{C}-\mathrm{H}$ bond cleavage for $\mathrm{CH}_{3} \mathrm{D}\left(v_{4}\right), \mathrm{CH}_{2} \mathrm{D}_{2}\left(v_{6}\right)$, and $\mathrm{CHD}_{3}\left(v_{1}\right)$. Hundt et al. (83) continued these bond selectivity measurements on $\mathrm{Pt}(111)$ for other $\mathrm{C}-\mathrm{H}$ excited states of $\mathrm{CH}_{3} \mathrm{D}$ and $\mathrm{CH}_{2} \mathrm{D}_{2}$ and found their chemisorption to be both bond selective and mode specific.

Vibrational excitation can also be used to make the dissociative chemisorption of methane isotope selective. Utz and coworkers (84) used a molecular beam of methane with natural abundances of ${ }^{12} \mathrm{CH}_{4}(98.9 \%)$ and ${ }^{13} \mathrm{CH}_{4}(1.1 \%)$; they demonstrated that exciting the antisymmetric stretch of ${ }^{13} \mathrm{CH}_{4}$ led to a ninefold enrichment of ${ }^{13} \mathrm{C}$ deposited on the surface. With optimization of the experimental conditions, the authors suggested that this selectivity for ${ }^{13} \mathrm{CH}_{4}$ could be increased to over $99 \%$.

Spatial control over the deposition of methane dissociation products has also been demonstrated through laser excitation; Utz and coworkers (85) used the Doppler shift in a diverging molecular beam to selectively excite the $v_{3}$ mode of $\mathrm{CH}_{4}$ only in the center of the molecular beam by a single-mode laser. As the vibrationally excited molecules are the most reactive, this leads to a narrow stripe of adsorbates on the surface. Through intentional misalignment of their multipass cell, used to increase the number of vibrationally excited molecules, they could also deposit a pattern of equally spaced stripes of adsorbates on the $\mathrm{Ni}(100)$ surface. Such isotopic and spatial control is of potentially great value in chemical vapor deposition. 
Figure 2

The reflection absorption infrared spectra obtained by Chen et al. (82) for the dissociative chemisorption of (a) $\mathrm{CH}_{3} \mathrm{D},\left(\right.$ b) $\mathrm{CH}_{2} \mathrm{D}_{2}$, and (c) $\mathrm{CHD}_{3}$ on

$\operatorname{Pt}(111)$ at $T_{\mathrm{s}}=$ $150 \mathrm{~K}$. The laser-off spectra (blue) yield statistical branching ratios for $\mathrm{C}-\mathrm{H}$ :C-D cleavage. The laser-on spectra (red) show that only $\mathrm{C}-\mathrm{H}$ cleavage occurs when a $\mathrm{C}-\mathrm{H}$ stretch vibration is excited in the incident $\mathrm{CH}_{3} \mathrm{D}\left(v_{4}\right)$, $\mathrm{CH}_{2} \mathrm{D}_{2}\left(v_{6}\right)$, or $\mathrm{CHD}_{3}\left(v_{1}\right)$. Figure adapted from Reference 28.
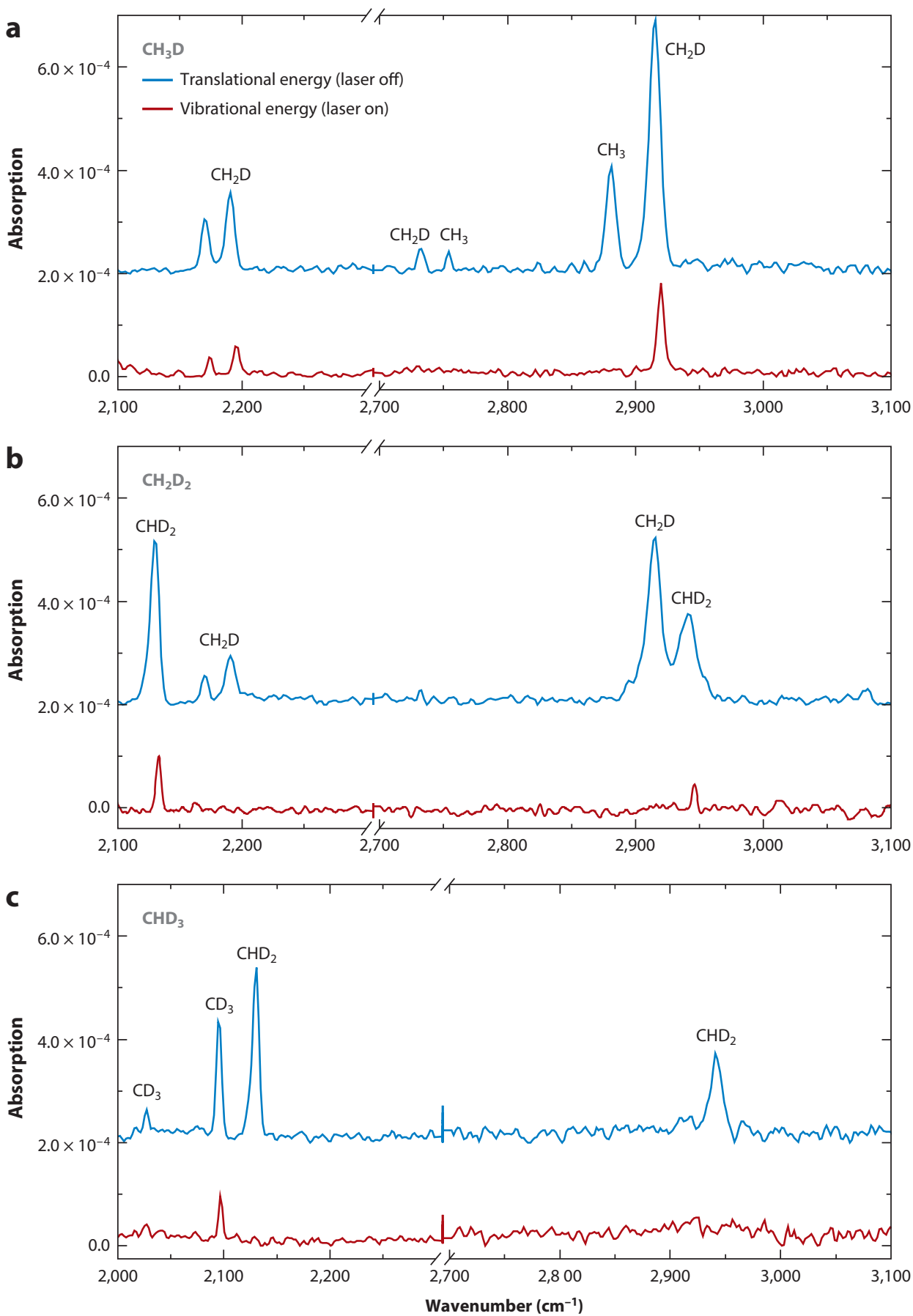


\subsection{Role of Rotation}

The role of rotational excitation in the dissociative chemisorption of methane was studied by Juurlink et al. (86) on $\mathrm{Ni}(100)$. They excited the four lowest rotational levels of $\mathrm{CH}_{4}\left(v_{3}\right)$ and found that the sticking coefficient varied by less than a factor of two. This suggests an absence of steering effects that would lead to an increase in sticking coefficient as the rotational level decreases. Additionally, they excited the $v_{3}, J=1$ state using P-, Q-, and R-branch excitation to probe for any differences in reactivity between the three Coriolis levels of the $v_{3}$ vibration. The authors found that the reactivity for each state was the same, within experimental error.

\subsection{Role of Reactant Alignment}

The lack of significant steering forces is further supported by measurements of Yoder et al. $(87,88)$, who studied alignment effects in methane dissociation on $\mathrm{Ni}(111), \mathrm{Ni}(100)$, and $\mathrm{Ni}(110)$. Using linearly polarized light to prepare and align $\mathrm{CH}_{4}\left(v_{3}\right)$, they determined that the sticking coefficient was largest for molecules with the $\mathrm{C}-\mathrm{H}$ stretch amplitude aligned parallel to the surface and smallest for those with the amplitude aligned perpendicular to the surface, for all three nickel surfaces. On the $\mathrm{Ni}(111)$ surface, the authors found that the reactivity increased by $40 \%$, an observation that has recently been reproduced in simulations using quasi-classical trajectory calculations (89).

Yoder et al. also investigated how the reactivity depends on the azimuthal alignment of the $\mathrm{C}-\mathrm{H}$ stretch on the corrugated $\mathrm{Ni}(110)$ surface. By rotating the surface about the surface normal, they could align the $\mathrm{C}-\mathrm{H}$ stretch amplitude in the plane of the surface either parallel or perpendicular to the close-packed rows of $\mathrm{Ni}$ atoms. The measurements showed a higher reactivity when the $\mathrm{C}-\mathrm{H}$ stretch amplitude was aligned perpendicular to the rows than when it was parallel to the rows, demonstrating the effect of surface structure on the sticking coefficient.

\subsection{Role of Incidence Angle and Impact Site}

First-principles calculations for $\mathrm{CH}_{4}$ dissociation show how the dissociation barrier depends on the impact site of the incident reactant. For example, on $\mathrm{Ni}(111)$ and $\mathrm{Pt}(111)$, the minimum barrier is calculated for dissociation over the top site (90). Bisson et al. (91) exploited shadowing effects on a corrugated $\mathrm{Pt}(110)-(1 \times 2)$ surface to control the impact site of incident methane in order to measure the relative reactivity of ridge and trough sites. To do this, they determined the polar-angle dependence of the $\mathrm{CH}_{4}\left(v_{3}\right)$ reactivity for incidence parallel and perpendicular to the close-packed rows of $\mathrm{Pt}$ atoms. For incidence perpendicular to the rows, the ridges effectively shadow the troughs for angles greater than $40^{\circ}$, whereas when directed parallel to the rows, the molecules sample the ridges and troughs equally. A larger sticking coefficient was measured with the beam perpendicular to the rows, where $\mathrm{CH}_{4}$ collides preferentially with the ridge sites, demonstrating that the reactivity of the ridge sites is larger than that of the troughs. Bisson et al. (67) also found that the sticking coefficient on the corrugated $\operatorname{Pt}(110)-(1 \times 2)$ surface was larger than that obtained under the same conditions on the flatter $\operatorname{Pt}(111)$ surface. This was attributed to the lower coordination number of the atoms in the ridges, which lowered the activation barrier for the reaction at these sites.

\subsection{Role of Surface Temperature}

The influence of the surface temperature on the sticking coefficient has been studied by Campbell and coworkers $(92,93)$ for $\mathrm{CH}_{4}\left(v_{3}\right)$ on $\mathrm{Ni}(111)$. Oxygen and hydrogen titrations were used to quantify the adsorbed species. The surface temperature was varied between $90 \mathrm{~K}$ and $475 \mathrm{~K}$, and it was found that the reactivity increased by three orders of magnitude when $E_{\mathrm{t}}$ of the incident beam 


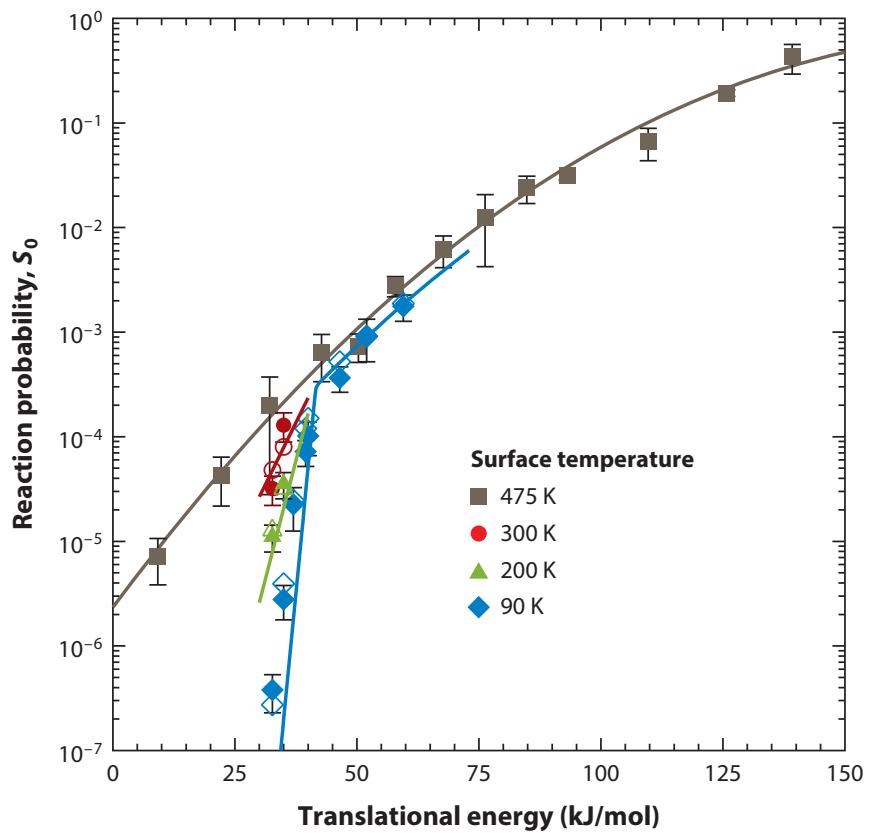

Figure 3

The sticking coefficient for the dissociative chemisorption of $\mathrm{CH}_{4}\left(\nu_{3}\right)$ on $\mathrm{Ni}(111)$ for different surface temperatures. At $T_{\mathrm{s}}=90 \mathrm{~K}$, a sharp threshold is observed at $E_{\mathrm{t}}=42 \mathrm{~kJ} / \mathrm{mol}$. Below $E_{\mathrm{t}}=42 \mathrm{~kJ} / \mathrm{mol}, S_{0}\left(v_{3}\right)$ strongly depends on $T_{\mathrm{s}}$, whereas the dependence is less pronounced at higher incident energies. Figure adapted from Reference 93 with permission. Copyright 2015 American Chemical Society.

increased from $34 \mathrm{~kJ} / \mathrm{mol}$ to $42 \mathrm{~kJ} / \mathrm{mol}$ at $T_{\mathrm{s}}=90 \mathrm{~K}$, but only by a factor of two at $T_{\mathrm{s}}=475 \mathrm{~K}$. This observation was attributed to an increase in the thermal motion of the surface atoms as $T_{\mathrm{s}}$ increases. The calculations of Jackson and coworkers $(23,94,95)$ showed how moving a surface atom above the surface plane reduces the activation barrier for dissociative chemisorption. Their calculations predict an efficacy of 1.1 for surface phonons, making phonon excitation more efficient than $E_{\mathrm{t}}$ at promoting the dissociation of $\mathrm{CH}_{4}$. As shown in Figure 3, the results at the lowest surface temperature show a sharp threshold in sticking coefficient at $E_{\mathrm{t}}=42 \mathrm{~kJ} / \mathrm{mol}$, which, the authors argued, corresponds to the minimum $E_{\mathrm{t}}$ needed to overcome the activation barrier, as at $T_{\mathrm{s}}=90 \mathrm{~K}$ there will be little reduction in the barrier height through motion of the surface atoms. Combining this $E_{\mathrm{t}}$ with the $36 \mathrm{~kJ} / \mathrm{mol}$ of $E_{\mathrm{v}}$ in $v_{3}$ gives an experimentally determined activation barrier to the reaction of $78 \mathrm{~kJ} / \mathrm{mol}$, in good agreement with the value from calculations (93).

\subsection{The Transition Metal Surface: Ni(111) Versus Pt(111) Versus Ir(111)}

Whereas most of the quantum state-resolved reactivity studies reported so far have focused on platinum and nickel surfaces, Dombrowski et al. (74) studied the dissociation of $\mathrm{CH}_{4}\left(v_{3}\right)$ on $\operatorname{Ir}(111)$. They observed a minimum in the sticking coefficient near $E_{\mathrm{t}}=10 \mathrm{~kJ} / \mathrm{mol}$, with $S_{0}\left(v_{3}\right)$ increasing at both higher and lower values of $E_{\mathrm{t}}$. The increase in $S_{0}\left(v_{3}\right)$ with decreasing $E_{\mathrm{t}}$ is indicative of a precursor-mediated pathway, where the methane is initially trapped in a physisorbed precursor state before dissociation occurs. Precursor-mediated dissociation has not been seen in state-resolved studies of $\mathrm{CH}_{4}$ on $\mathrm{Pt}(111)$ and $\mathrm{Ni}(111)$, but was observed for $E_{\mathrm{t}}<9.6 \mathrm{~kJ} / \mathrm{mol}$ in a 
study by Walker \& King (96) on $\operatorname{Pt}(110)-(1 \times 2)$, although their measurements were not quantum state-resolved.

The authors also found that $\eta\left(v_{3}\right)$ for the dissociation of $\mathrm{CH}_{4}$ on $\operatorname{Ir}(111)$ was the same for both the precursor-mediated pathway and direct chemisorption, suggesting that $E_{\mathrm{v}}$ remains in the molecule on the several-picosecond timescale in which the $\mathrm{CH}_{4}$ is trapped before it dissociates. Also, $\eta\left(v_{3}\right)=0.43$ for $\operatorname{Ir}(111)$ (74), which is smaller than for $\mathrm{Ni}(111)\left[\eta\left(v_{3}\right)=1.25(69)\right]$ and $\operatorname{Pt}(111)$ $\left[\eta\left(v_{3}\right)=0.71(72)\right]$. The magnitude of $\eta\left(v_{3}\right)$ is related to the length of the dissociating C-H bond at the transition state $(97,98)$, with the largest efficacy associated with the longest bond. This suggests that preparing the reactant in a state that distorts the molecules toward the transitionstate structure enhances its reactivity. Guo and coworkers $(99,100)$ applied this idea in their sudden vector projection (SVP) model by calculating the projection of the initially prepared vibrational state onto the transition-state structure to predict the ordering of the vibrational efficacies for different vibrational states.

\section{DISSOCIATIVE CHEMISORPTION OF HYDROGEN}

\subsection{Recombinative Desorption of $\mathrm{D}_{2}$ on Copper}

The recombination of two adsorbed $\mathrm{H}$ atoms to form desorbing $\mathrm{H}_{2}$ on a transition metal surface is the time-reverse process of the dissociative chemisorption of $\mathrm{H}_{2}$. $\mathrm{H}$-atom permeation through a $\mathrm{Cu}$ single crystal can be used to produce a steady stream of $\mathrm{H}_{2}$ desorbing from the copper surface, which can be detected with quantum state resolution by REMPI. Using the principle of detailed balance, the measured rovibrational state distributions of the desorbing $\mathrm{H}_{2}$ (or $\mathrm{D}_{2}$ ) can be converted to state-resolved sticking coefficients for hydrogen chemisorption.

Michelsen et al. $(101,102)$ observed both vibrationally and rotationally excited $\mathrm{D}_{2}$ desorbing from $\mathrm{Cu}(111)$. They found that the dissociative chemisorption is promoted most efficiently by incident $E_{\mathrm{t}}$ and least efficiently by rotational energy. The vibrational efficacy was found to be less than one for all vibrational states, decreasing with increasing $v$ (103).

For $J=0$ to $J=5, S_{0}(v)$ was found to decrease with increasing $J$ before increasing again for $J>$ 5 , with this trend being most marked for $v=0$. This observation was attributed to two competing factors. The first is the fact that with increasing rotational excitation, $\mathrm{D}_{2}$ spends less time sampling the most favorable dissociation geometry, which increases the effective dissociation barrier. This effect dominates between $J=0$ and $J=5$, which leads to the observed decrease in the sticking coefficient. The second effect, which dominates at higher $J$, is the increase in rotational energy of $\mathrm{D}_{2}$ with increasing $J$. For $J>5$, the rotational energy helps to overcome the dissociation barrier and thereby increases the sticking coefficient. At higher $J$, the effect of the orientation on the observed reactivity is less significant than at low $J$ because the faster rotation means that the molecule effectively samples a rotationally averaged potential.

Auerbach and coworkers $(104,105)$ further investigated the anisotropy of the PES for $\mathrm{D}_{2}$ dissociation on $\mathrm{Cu}(111)$. By using a linearly polarized laser for REMPI detection, they were able to determine the alignment of the desorbing $\mathrm{D}_{2}$. At the lowest $E_{\mathrm{t}}$ studied, they observed a strong steric effect, which indicated that the dissociation would be promoted by aligning the $\mathrm{D}_{2}$ bond parallel to the plane of the surface. Increasing $E_{\mathrm{t}}$ reduces this preference, again because the increased energy allows the molecules to dissociate in less favored geometries. Auerbach and coworkers also observed that the alignment effect increases with increasing $J$. The authors argued that the smaller alignment effect at lower $J$ can be attributed to a steering mechanism, where the anisotropy of the potential can steer the molecule into the most favored geometry independent of the initial approach geometry.
SVP: sudden vector projection 


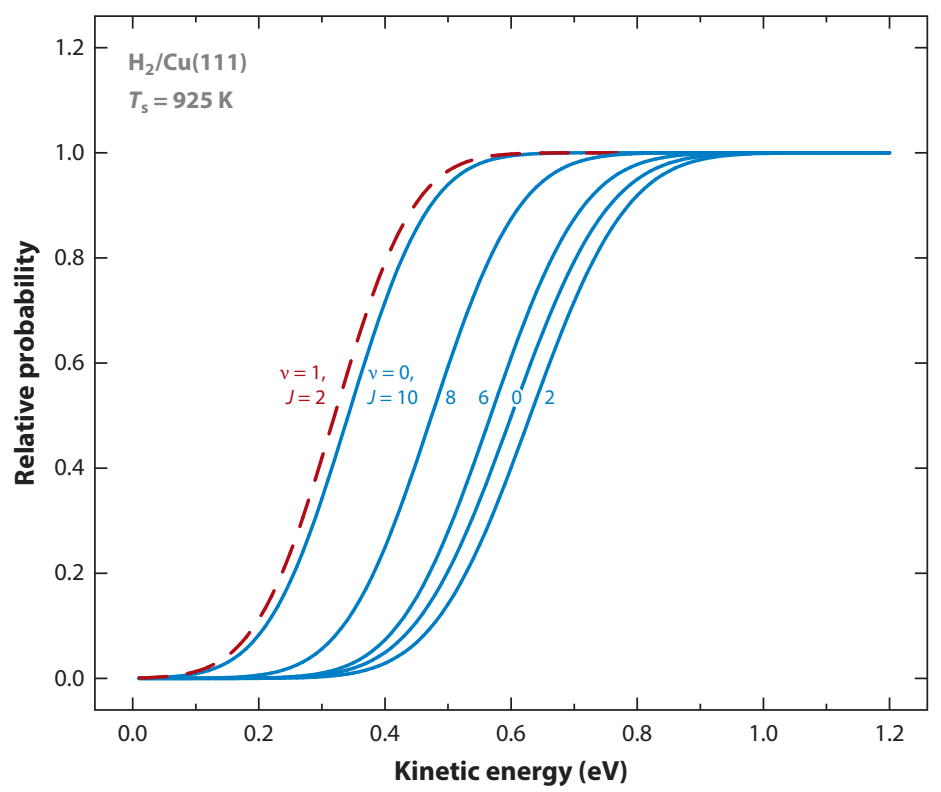

Figure 4

The relative sticking coefficients obtained for the dissociative chemisorption of $\mathrm{H}_{2}$ on $\mathrm{Cu}(111)$ from recombinative desorption measurements at $T_{\mathrm{s}}=925 \mathrm{~K}$. The curve for $v=0, J=2$ is furthest right, reflecting the decrease in sticking coefficient observed at low $J$ as $J$ increases. The similar positions of the $v=0, J=10$ and $v=1, J=2$ curves demonstrate how much rotation enhances the reactivity at higher $J$. Figure adapted from Reference 107 with permission. Copyright 1995 AIP Publishing.

The trends observed for $\mathrm{D}_{2}$ on $\mathrm{Cu}(111)$ are qualitatively similar for $\mathrm{HD}$ (106) and $\mathrm{H}_{2}$ (107) on the same surface, as well as for $\mathrm{Cu}(110)$ (108). For $\mathrm{H}_{2}$ on $\mathrm{Cu}(111)$, the sticking coefficient was observed to decrease with increasing $J$ up to $J=4$. As with $\mathrm{D}_{2}$, it was found that $E_{\mathrm{t}}$ was the most efficient at promoting dissociation, and rotational energy the least efficient. The relative probabilities of dissociation obtained from this study are presented in Figure 4.

The studies above were restricted to $T_{\mathrm{s}}>850 \mathrm{~K}$, due to the requirement that a significant number of $\mathrm{H}$ atoms or $\mathrm{D}$ atoms needed to diffuse through the bulk copper crystal. By using a molecular beam of $\mathrm{H}_{2}$ or $\mathrm{D}_{2}$, Auerbach and coworkers (109) could reduce the temperature of the $\mathrm{Cu}(111)$ surface to $400 \mathrm{~K}$. They measured the rovibrational distribution of the incident and scattered molecular beam using REMPI and TOF methods, and could relate the different rovibrational distributions measured before and after the surface to the probability of molecules becoming adsorbed on the surface. The authors observed the same dependence of the sticking coefficient on $J$ as observed in the recombinative desorption measurements presented above at higher surface temperatures. Murphy \& Hodgson (110) further investigated the effect of $T_{\mathrm{s}}$ on the dissociative chemisorption of $\mathrm{H}_{2}$ and $\mathrm{D}_{2}$ on $\mathrm{Cu}(111)$. They found that as $T_{\mathrm{s}}$ increased between $370 \mathrm{~K}$ and $900 \mathrm{~K}$, the sticking coefficient increased at $E_{\mathrm{t}}$ below approximately $70 \mathrm{~kJ} / \mathrm{mol}$. This was attributed to the reduction in the activation barrier due to the increased thermal motion of the surface atoms at higher $T_{\mathrm{s}}$.

Even the simplest molecule-surface reactions, such as the dissociation of $\mathrm{H}_{2}$ and $\mathrm{D}_{2}$ on $\mathrm{Cu}$, still present a major challenge for theoreticians to develop first-principles models with chemical accuracy. Kroes \& Diaz (111) detailed the current state of theoretical descriptions in a recent review. 


\subsection{Dissociative Chemisorption of $\mathbf{H}_{2}$ on Palladium}

In contrast to the dissociative chemisorption of $\mathrm{H}_{2}$ on $\mathrm{Cu}(111)$, the dissociative chemisorption of $\mathrm{H}_{2}$ on $\mathrm{Pd}(111)$ occurs without a significant activation barrier. Gostein \& Sitz (112) determined the dissociation probability of $\mathrm{H}_{2}$ on a $\mathrm{Pd}(111)$ surface by measuring the difference between the incident and scattered $\mathrm{H}_{2}$ fluxes. They observed a decrease in sticking coefficient with increasing $J$ for $J=0$ to $J=3$, before it increased for $J=4$ and $J=5$, again providing evidence that steering effects dominated the trends in the reactivity observed at the lowest $J$. Rettner \& Auerbach (113) also studied the dissociation of $\mathrm{H}_{2}$ on $\mathrm{Pd}(100)$ and found that the sticking coefficient decreased with increasing rotational state up to $J=3$, the highest rotational state that was investigated. The alignment dependence of the sticking coefficient of $\mathrm{D}_{2}$ on $\mathrm{Pd}(100)$ was measured by Wetzig et al. (114). They found that the $\mathrm{D}_{2}$ in $v=0$ desorbed with the bond axis preferentially aligned parallel to the surface, with the alignment increasing with increasing $J$ up to $J=6$. In contrast, no alignment dependence was observed for $v=1$.

\subsection{Dissociative Chemisorption and Recombinative Desorption of $\mathrm{D}_{2}$ on Silver}

Hodgson and coworkers (115) studied the endothermic dissociation of $\mathrm{D}_{2}$ on $\mathrm{Ag}(111)$. Initially they studied the dissociation directly by using seeded molecular beams of $\mathrm{D}_{2}$ as a function of nozzle temperature. With increasing nozzle temperature, both $E_{\mathrm{t}}$ and the vibrational excitation of $\mathrm{D}_{2}$ in the beam increase. Their analysis shows a decrease in the translational energy threshold required to observe $\mathrm{D}_{2}$ dissociation with increasing $v=0$ up to $v=4$, with an averaged vibrational efficacy of 0.5 .

Later, Murphy \& Hodgson extended these experiments to the recombinative desorption of $\mathrm{D}_{2}$ (116) and $\mathrm{H}_{2}$ (117) from $\mathrm{Ag}(111)$ for $T_{\mathrm{s}}=300 \mathrm{~K}$ and $570 \mathrm{~K}$. At $300 \mathrm{~K}$, thermal desorption of $\mathrm{D}_{2}(v=0)$ dominated, indicative of a precursor pathway for the dissociation reaction. At $T_{\mathrm{s}}=570 \mathrm{~K}$, the $E_{\mathrm{t}}$ distribution of the desorbing $\mathrm{D}_{2}(v=0)$ was bimodal, with a higher energy component indicating a direct dissociation pathway. The direct pathway was suggested to open at the higher $T_{\mathrm{s}}$ due to thermal surface-atom motion broadening the distribution of activation barriers for the dissociation. For $\mathrm{D}_{2}(v=1)$ desorption, only the higher $E_{\mathrm{t}}$ component was observed.

\subsection{Recombinative Desorption of $\mathrm{H}_{2}$ on Silicon}

Zare and coworkers (118-121) studied the dynamics of hydrogen recombination on $\mathrm{Si}(100)$ and $\mathrm{Si}(111)-(7 \times 7)$. They dosed the silicon surfaces with $\mathrm{Si}_{2} \mathrm{H}_{6}$ to produce adsorbed $\mathrm{H}$ atoms, then increased the surface temperature and detected the desorbing $\mathrm{H}_{2}$ using REMPI/TOF methods. The rovibrational state distributions of the desorbing hydrogen measured from both silicon surfaces were the same, within experimental error. Desorbing $\mathrm{H}_{2}$ was detected in both $v=0$ and $v=1$, with the $v=1$ population 20 times higher than predicted from a Boltzmann distribution at $T_{\mathrm{s}}=800 \mathrm{~K}$, indicating that vibrational excitation should enhance the reverse dissociative chemisorption reaction. The observed rotational distributions indicated a steering mechanism that dominated at low $J$, similar to results obtained for copper and palladium surfaces. Zare and coworkers (119) also studied the desorption of $\mathrm{HD}$ and $\mathrm{D}_{2}$, finding that the ratio of molecules desorbing in $v=0$ and $v=1$ was the same in each case and that steering was observed at low $J$.

In a more recent study, Dürr \& Höfer (122) used a molecular beam of hydrogen incident on $\mathrm{Si}(111)$ and $\mathrm{Si}(001)$ to study $\mathrm{H}_{2}$ dissociation. By changing the nozzle temperature, they determined the sticking coefficients for $v=1$ and $v=2$, finding that the efficacy $\eta(v=1)$ is higher than $\eta(v=2)$. 


\section{DISSOCIATIVE CHEMISORPTION OF SILANE ON Si(100)-(2 × 1)}

Bisson et al. (59) studied the dissociative chemisorption of $\mathrm{SiH}_{4}$ on $\mathrm{Si}(100)-(2 \times 1)$ using SIMS detection. The incident $\mathrm{SiH}_{4}$ was prepared in the local-mode $\mathrm{Si}-\mathrm{H}$ stretch overtone states $|1100\rangle$ and $|2000\rangle$ (123). $\mathrm{SiH}_{4}$ dissociation was observed to be vibrationally activated and mode specific. The $\mathrm{SiH}_{4}$ prepared in $|2000\rangle$ was found to be more reactive than $\mathrm{SiH}_{4}|1100\rangle$ over the full range of $E_{\mathrm{t}}=6-116 \mathrm{~kJ} / \mathrm{mol}$ probed by the experiments. Increasing $T_{\mathrm{s}}$ from $373 \mathrm{~K}$ to $473 \mathrm{~K}$ increased the sticking coefficients for $E_{\mathrm{t}}>20 \mathrm{~kJ} / \mathrm{mol}$ but decreased them for $E_{\mathrm{t}}<20 \mathrm{~kJ} / \mathrm{mol}$. Furthermore, below $E_{\mathrm{t}}=20 \mathrm{~kJ} / \mathrm{mol}$, the sticking coefficient increased with decreasing $E_{\mathrm{t}}$, indicative of precursormediated chemisorption. To be trapped in a precursor state, the incident $\mathrm{SiH}_{4}$ must lose most of its momentum perpendicular to the surface on impact. Momentum transfer from $\mathrm{SiH}_{4}$ to $\mathrm{Si}(100)$ is efficient due to the similar masses of the collision partners. The fact that vibrational activation of the $\mathrm{SiH}_{4}$ chemisorption was also observed for the precursor pathway can be rationalized by the absence of fast vibrational energy relaxation to electron-hole pair excitation of the surface, as the $\mathrm{SiH}_{4}$ vibrational energy $\left(\sim 4,300 \mathrm{~cm}^{-1}\right)$ is below the band gap $\left(\sim 8,950 \mathrm{~cm}^{-1}\right)$ of the $\mathrm{Si}(100)$ surface.

\section{DISSOCIATIVE CHEMISORPTION OF WATER ON Ni(111)}

Hundt et al. (124) investigated the effect of $E_{\mathrm{t}}$ and $E_{\mathrm{v}}$ on the dissociative chemisorption of $\mathrm{D}_{2} \mathrm{O}$ on $\mathrm{Ni}(111)$ by comparing the laser-off reactivity with the state-resolved reactivity of $\mathrm{D}_{2} \mathrm{O}$ with one or two quanta of antisymmetric $\left(v_{3}\right) \mathrm{O}-\mathrm{D}$ stretch excitation. As shown in Figure 5, both

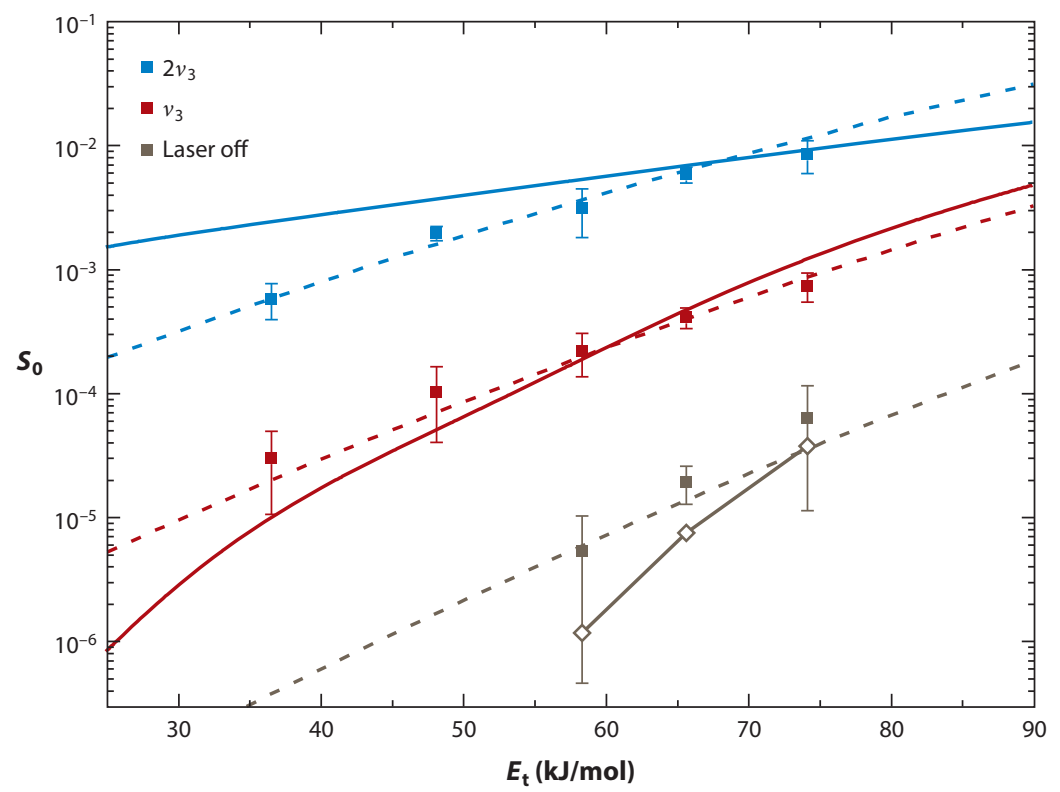

Figure 5

State-resolved sticking coefficients for the dissociative chemisorption of $\mathrm{D}_{2} \mathrm{O}$ on a $\mathrm{Ni}(111)$ surface at $T_{\mathrm{s}}=300 \mathrm{~K}$. Red and blue squares are state-resolved reactivity measurements for one and two quanta of O-D stretch excitation, respectively. Gray squares show the experimental laser-off reactivity of $\mathrm{D}_{2} \mathrm{O}$. Dashed lines are S-shaped reactivity curves (24) fitted to the data points, and solid lines are the results of quantum dynamics calculations by Jiang \& Guo (124). Open diamonds show the calculated laser-off reactivity, including thermally excited $\mathrm{D}_{2} \mathrm{O}$. Figure adapted from Reference 124 . 
$E_{\mathrm{v}}$ and $E_{\mathrm{t}}$ increase the reactivity, but to different extents. The authors found a large increase in reactivity even for the second quantum of $\mathrm{O}-\mathrm{D}$ stretch vibration, indicating a vibrational efficacy $\eta\left(2 v_{3}\right)$ greater than one. The efficacy for excitation of the first quantum of O-D stretch excitation $\eta\left(v_{3}\right)$ could not be determined accurately by the experiments because the $S_{0}$ (laser off) data were measured for different nozzle temperatures between $573 \mathrm{~K}$ and $773 \mathrm{~K}$, where the $\mathrm{D}_{2} \mathrm{O}$ reactivity is dominated by the thermal vibrationally excited $\mathrm{D}_{2} \mathrm{O}$ in the molecular beam.

In the same publication, Jiang \& Guo (124) reported quantum dynamics calculations for $\mathrm{D}_{2} \mathrm{O}$ dissociation on $\mathrm{Ni}(111)$ on the basis of a global six-dimensional PES calculated using DFT. Initially, the calculated sticking coefficients were much higher than the experimental values, most likely due to an underestimation of the activation barrier calculated using the PW91 functional. Increasing the barrier improved the agreement with experiment, as shown in Figure 5. The model could then be used to calculate the $\mathrm{D}_{2} \mathrm{O}$ laser-off reactivity due to thermal vibrational reactivity, as well as the true $v=0$ reactivity. The authors determined the efficacy for one quantum of $\mathrm{O}-\mathrm{D}$ stretch excitation to be $\eta\left(v_{3}\right)=1.7$, significantly larger than that obtained for the antisymmetric stretch of $\mathrm{CH}_{4}$ on the same surface. This indicates that the dissociation of $\mathrm{D}_{2} \mathrm{O}$ is governed by a late barrier in the PES, a result supported by calculations of the transition-state structure, which showed significant elongation of the dissociating $\mathrm{O}-\mathrm{D}$ bond.

The results of this combined experiment/theory study highlight the value of detailed experimental data for guiding the development of first-principles theory to arrive at a predictive understanding of processes at the gas-surface interface.

\section{SUMMARY}

The combination of molecular beams and quantum state-specific reactant preparation or product detection by laser radiation enables detailed studies of gas-surface reactions at a molecular level. These experiments demonstrate that a molecule's reactivity depends not only on the total initial incident energy, but also on the energy partitioning between the translational, rotational, and vibrational degrees of freedom, as well as on the reactant's quantum state. Mode specificity and bond selectivity had been observed previously in reactions in the gas phase (125-127), but were not necessarily expected to occur for gas-surface reactions due to the availability of many degrees of freedom of the solid surface for energy redistribution and relaxation. Harrison and coworkers (77$80,128)$ developed a statistical theory for chemisorption reactions, which assumed that complete IVR occurred in a physisorbed complex consisting of the reactant molecule and a certain number of surface atoms. The model was claimed to quantitatively describe the available experimental data on methane chemisorption using only the dissociation barrier height, the number of surface atoms in the complex, and a single phonon frequency characterizing the surface as input variables. However, a statistical model for chemisorption is inconsistent with the mode specificity, bond selectivity, and steric effects observed in the quantum state-resolved reactivity measurements described above.

The state-resolved experiments for methane chemisorption clearly demonstrate that IVR is far from complete before dissociation occurs when state-prepared reactants collide with a metal surface. The picture that emerges is one where only limited surface-induced IVR can occur because of the interaction between the incident reactant and the solid surface, which can even be responsible for the observed mode specificity. Halonen et al. (129) described such surface-induced IVR for C$\mathrm{H}$ stretch-excited $\mathrm{CH}_{4}$ prepared in the normal modes $v_{1}$ and $v_{3}$. If the incident reactant is initially prepared in a molecular eigenstate, no IVR will occur as long as there is no interaction with the target surface. However, close to the surface $(<0.5 \mathrm{~nm})$, the molecule-surface interaction will initiate this surface-induced IVR process because the initially prepared eigenstate of the isolated
PW91: Perdew \& Wang 91 exchange correlation functional 
RPH: reaction path Hamiltonian

AIMD: ab initio molecular dynamics molecule is no longer an eigenstate of the combined molecule-surface system. Instead, it can be described as a time-dependent superposition of the molecular eigenstates.

Jackson and coworkers $(23,130-134)$ have developed a dynamical approach that includes surface-induced IVR to model the dissociative chemisorption of methane on transition metal surfaces. In their reaction path Hamiltonian (RPH) model, they calculate the minimum energy path from reactants to products using DFT and assume that any motion orthogonal to this path can be described harmonically. They then propagate vibrationally adiabatic wavepackets for each vibrational mode of the molecule on the PES to determine the extent to which each mode softens and couples to the reaction path. The model also includes vibrationally nonadiabatic transitions between the vibrational adiabats. The calculations show that both mode softening and vibrationally nonadiabatic transitions contribute to the state-specific reactivity. The RPH model reproduces both the bond selectivity (130) and the mode specificity $(23,131-133)$ observed in the dissociative chemisorption of methane. It has also been used to model the dissociation of water on $\mathrm{Ni}(111)$ (134).

At the opposite end of the spectrum, the SVP model proposed by Guo and coworkers (99, 100) neglects any surface-induced IVR, assuming that the timescale of the collision is too short. The SVP model, which is essentially an extension of Polanyi's rules (135) to a multidimensional PES, calculates the projection of the reactant's normal-mode vectors onto the reaction coordinate at the transition state. An initial state with a large projection onto the reaction coordinate at the transition state is expected to result in a large vibrational efficacy. This model has successfully captured the mode specificity observed in the deuterated isotopologues of methane $(99,100,136)$, as well as the high vibrational efficacy seen in the dissociation of water $(137,138)$.

Rather than using a quantum approach to propagate the dynamics, Kroes and coworkers (22, 139-144) use quasi-classical trajectory calculations in their ab initio molecular dynamics (AIMD) simulations of gas-surface reactions. One advantage of the AIMD treatment is that it includes all molecular degrees of freedom as well as the surface-atom motion, which is not yet possible using quantum dynamics. However, application of the AIMD model is restricted to incident energies above the activation barrier, where tunneling is not important. These full-dimensional calculations were used to test some of the approximations made in reduced-dimensionality calculations (139). They have been used to model $\mathrm{H}_{2}$ on copper $(22,140)$ and $\mathrm{CHD}_{3}$ on $\mathrm{Pt}(111)$ (141-143) and on $\mathrm{Ni}(111)(139,144)$, but extension to $\mathrm{CH}_{4}$ is difficult due to artificial IVR that can occur between bonds of the same frequency in classical calculations.

Although there has been significant progress in developing a predictive understanding of reactions at the gas-surface interface, the extent to which the BOA is applicable remains unclear. In the studies presented in this review, there is no conclusive evidence that nonadiabatic effects influence the dissociation dynamics. Recent experiments on the dissociation of $\mathrm{HCl}$ on $\mathrm{Au}(111)$ by Shirhatti et al. (145) measured the sticking coefficient to be much lower than predicted theoretically (146). A possible reason might be that the calculations neglect nonadiabatic effects, which have been observed in surface scattering experiments for the same system (14-16). Work by Hasselbrink and coworkers (147-149) has detected the possible presence of nonadiabatic effects in the recombination of $\mathrm{H}$ atoms on gold surfaces, which implies their presence in the reverse dissociative chemisorption reaction. Further quantum state-resolved reactivity studies on the dissociative chemisorption in these two systems might yield experimental evidence of electronically nonadiabatic effects.

The quantum state-resolved studies of gas-surface reactions described in this review give detailed insight into the complexity of these processes at a microscopic level. These experimental results provide a valuable resource to benchmark theoretical descriptions of dissociative 
chemisorption. The interplay between experiment and theory significantly contributes to the goal of developing a predictive understanding of reactions at the gas-surface interface.

\section{DISCLOSURE STATEMENT}

The authors are not aware of any affiliations, memberships, funding, or financial holdings that might be perceived as affecting the objectivity of this review.

\section{ACKNOWLEDGMENTS}

We acknowledge the important contributions of doctoral students Mathieu Schmid, Plinio Maroni, Tung T. Dang, Marco Sacchi, Bruce L. Yoder, Li Chen, Morten Hundt, Maarten van Reijzen, Jörn Werdecker, and Ana Gutiérrez-González, as well as of postdoctoral associates Régis Bisson and Hirokazu Ueta, at the EPFL. We also thank Andreas Osterwalder and Mark Brouard for their critical reading of a draft of this manuscript.

\section{LITERATURE CITED}

1. Jasinski JM, Meyerson BS, Scott BA. 1987. Mechanistic studies of chemical vapor deposition. Annu. Rev. Phys. Chem. 38:109-40

2. Chorkendorff I, Niemantsverdriet JW. 2003. Concepts of Modern Catalysis and Kinetics. Weinheim, Ger.: Wiley

3. Pakhare D, Spivey J. 2014. A review of dry $\left(\mathrm{CO}_{2}\right)$ reforming of methane over noble metal catalysts. Chem. Soc. Rev. 43:7813-37

4. Ertl G. 1983. Primary steps in catalytic synthesis of ammonia. 7. Vac. Sci. Technol. A 1:1247-53

5. Rauscher H. 2001. The interaction of silanes with silicon single crystal surfaces: microscopic processes and structures. Surf. Sci. Rep. 42:207-328

6. Born M, Oppenheimer R. 1927. Quantum theory of molecules. Ann. Phys. 84:457-84

7. Bartels N, Golibrzuch K, Bartels C, Chen L, Auerbach DJ, et al. 2014. Dynamical steering in an electron transfer surface reaction: oriented $\mathrm{NO}\left(v=3,0.08<E_{\mathrm{i}}<0.89 \mathrm{eV}\right)$ relaxation in collisions with a $\mathrm{Au}(111)$ surface. F. Chem. Phys. 140:054710

8. Golibrzuch K, Shirhatti PR, Rahinov I, Auerbach DJ, Wodtke AM, Bartels C. 2014. Incidence energy dependent state-to-state time-of-flight measurements of $\mathrm{NO}(v=3)$ collisions with $\mathrm{Au}(111)$ : the fate of incidence vibrational and translational energy. Phys. Chem. Chem. Phys. 16:7602-10

9. Huang Y, Rettner CT, Auerbach DJ, Wodtke AM. 2000. Vibrational promotion of electron transfer. Science 290:111-14

10. Grätz F, Engelhart DP, Wagner RJV, Haak H, Meijer G, et al. 2013. Vibrational enhancement of electron emission in $\mathrm{CO}\left(\mathrm{a}^{3} \Pi\right)$ quenching at a clean metal surface. Phys. Chem. Chem. Phys. 15:14951-55

11. Schafer T, Bartels N, Golibrzuch K, Bartels C, Kockert H, et al. 2013. Observation of direct vibrational excitation in gas-surface collisions of $\mathrm{CO}$ with $\mathrm{Au}(111)$ : a new model system for surface dynamics. Phys. Chem. Chem. Phys. 15:1863-67

12. Grätz F, Engelhart DP, Wagner RJV, Meijer G, Wodtke AM, Schäfer T. 2014. CO ( $\left.a^{3} \Pi\right)$ quenching at a metal surface: evidence of an electron transfer mediated mechanism. 7. Chem. Phys. 141:044712

13. Shirhatti PR, Werdecker J, Golibrzuch K, Wodtke AM, Bartels C. 2014. Electron hole pair mediated vibrational excitation in $\mathrm{CO}$ scattering from $\mathrm{Au}(111)$ : incidence energy and surface temperature dependence. F. Chem. Phys. 141:124704

14. Ran Q, Matsiev D, Auerbach DJ, Wodtke AM. 2007. Observation of a change of vibrational excitation mechanism with surface temperature: $\mathrm{HCl}$ collisions with $\mathrm{Au}(111)$. Phys. Rev. Lett. 98:237601

15. Rahinov I, Cooper R, Yuan C, Yang X, Auerbach DJ, Wodtke AM. 2008. Efficient vibrational and translational excitations of a solid metal surface: state-to-state time-of-flight measurements of $\mathrm{HCl}(v=2$, $J=1$ ) scattering from $\mathrm{Au}(111)$. F. Chem. Phys. 129:214708 
16. Cooper R, Rahinov I, Yuan C, Yang X, Auerbach DJ, Wodtke AM. 2009. Efficient translational excitation of a solid metal surface: state-to-state translational energy distributions of vibrational ground state $\mathrm{HCl}$ scattering from $\mathrm{Au}(111)$. 7. Vac. Sci. Technol. A 27:907-12

17. Wodtke AM. 2016. Electronically non-adiabatic influences in surface chemistry and dynamics. Chem. Soc. Rev. 45:3641-57

18. Golibrzuch K, Bartels N, Auerbach DJ, Wodtke AM. 2015. The dynamics of molecular interactions and chemical reactions at metal surfaces: testing the foundations of theory. Annu. Rev. Phys. Chem. 66:399-425

19. Rahinov I, Cooper R, Matsiev D, Bartels C, Auerbach DJ, Wodtke AM. 2011. Quantifying the breakdown of the Born-Oppenheimer approximation in surface chemistry. Phys. Chem. Chem. Phys. 13:12680-92

20. Jiang B, Ren X, Xie D, Guo H. 2012. Enhancing dissociative chemisorption of $\mathrm{H}_{2} \mathrm{O}$ on $\mathrm{Cu}(111)$ via vibrational excitation. PNAS 109:10224-27

21. Diaz C, Olsen RA, Auerbach DJ, Kroes GJ. 2010. Six-dimensional dynamics study of reactive and non reactive scattering of $\mathrm{H}_{2}$ from $\mathrm{Cu}(111)$ using a chemically accurate potential energy surface. Phys. Chem. Chem. Phys. 12:6499-519

22. Nattino F, Genova A, Guijt M, Muzas AS, Díaz C, et al. 2014. Dissociation and recombination of $\mathrm{D}_{2}$ on $\mathrm{Cu}(111)$ : ab initio molecular dynamics calculations and improved analysis of desorption experiments. 7. Chem. Phys. 141:124705

23. Nave S, Tiwari AK, Jackson B. 2014. Dissociative chemisorption of methane on Ni and Pt surfaces: mode-specific chemistry and the effects of lattice motion. 7. Phys. Chem. A 118:9615-31

24. Luntz AC. 2000. A simple model for associative desorption and dissociative chemisorption. 7. Chem. Phys. 113:6901-5

25. Utz AL. 2009. Mode selective chemistry at surfaces. Curr. Opin. Solid State Mater. Sci. 13:4-12

26. Juurlink LBF, Killelea DR, Utz AL. 2009. State-resolved probes of methane dissociation dynamics. Prog. Surf. Sci. 84:69-134

27. Beck RD, Utz AL. 2013. Quantum-state resolved gas/surface reaction dynamics experiments. In Dynamics of Gas-Surface Interactions: Atomic-Level Understanding of Scattering Processes at Surfaces, ed. R Díez Muiño, HF Busnengo, pp. 179-212. Berlin: Springer

28. Chadwick H, Beck RD. 2016. Quantum state resolved gas-surface reaction dynamics experiments: a tutorial review. Chem. Soc. Rev. 45:3576-94

29. Diño WA, Kasai H, Okiji A. 2000. Orientational effects in dissociative adsorption/associative desorption dynamics of $\mathrm{H}_{2}\left(\mathrm{D}_{2}\right)$ on $\mathrm{Cu}$ and Pd. Prog. Surf. Sci. 63:63-134

30. Kleyn AW. 1992. Dissociation in molecule-surface collisions. F. Phys. Condens. Matter 4:8375

31. Michelsen HA, Auerbach DJ. 1991. A critical examination of data on the dissociative adsorption and associative desorption of hydrogen at copper surfaces. F. Chem. Phys. 94:7502-20

32. Hodgson A. 2000. State resolved desorption measurements as a probe of surface reactions. Prog. Surf. Sci. 63:1-61

33. Darling G, Hodgson A. 2010. Surface scattering: molecular collisions at interfaces. In Tutorials in Molecular Reaction Dynamics, ed. M Brouard, C Vallance, pp. 333-62. Cambridge, UK: R. Soc. Chem.

34. Dürr M, Höfer U. 2006. Dissociative adsorption of molecular hydrogen on silicon surfaces. Surf. Sci. Rep. 61:465-526

35. Dürr M, Höfer U. 2013. In Dynamics of Gas-Surface Interactions: Atomic-Level Understanding of Scattering Processes at Surfaces, ed. R Díez Muiño, HF Busnengo, pp. 239-66. Berlin: Springer

36. McCabe PR, Juurlink LBF, Utz AL. 2000. A molecular beam apparatus for eigenstate-resolved studies of gas-surface reactivity. Rev. Sci. Instrum. 71:42-53

37. Schmid MP, Maroni P, Beck RD, Rizzo TR. 2003. Molecular-beam/surface-science apparatus for stateresolved chemisorption studies using pulsed-laser preparation. Rev. Sci. Instrum. 74:4110-20

38. Ran Q, Matsiev D, Wodtke AM, Auerbach DJ. 2007. An advanced molecule-surface scattering instrument for study of vibrational energy transfer in gas-solid collisions. Rev. Sci. Instrum. 78:104104

39. Chen L, Ueta H, Bisson R, Beck RD. 2013. Quantum state-resolved gas/surface reaction dynamics probed by reflection absorption infrared spectroscopy. Rev. Sci. Instrum. 84:053902

40. Scoles G. 1988. Atomic and Molecular Beam Methods. New York: Oxford Univ. Press 
41. Kleyn AW. 2003. Molecular beams and chemical dynamics at surfaces. Chem. Soc. Rev. 32:87-95

42. Libuda J, Freund HJ. 2005. Molecular beam experiments on model catalysts. Surf. Sci. Rep. 57:157-298

43. Rettner CT, Pfnür HE, Auerbach DJ. 1985. Dissociative chemisorption of $\mathrm{CH}_{4}$ on W(110): dramatic activation by initial kinetic energy. Phys. Rev. Lett. 54:2716-19

44. Rettner CT, Pfnür HE, Auerbach DJ. 1986. On the role of vibrational energy in the activated dissociative chemisorption of methane on tungsten and rhodium. 7. Chem. Phys. 84:4163-67

45. Lee MB, Yang QY, Ceyer ST. 1987. Dynamics of the activated dissociative chemisorption of $\mathrm{CH}_{4}$ and implication for the pressure gap in catalysis: a molecular beam-high resolution electron energy loss study. 7. Chem. Phys. 87:2724-41

46. Holmblad PM, Wambach J, Chorkendorff I. 1995. Molecular beam study of dissociative sticking of methane on $\mathrm{Ni}(100)$. 7. Chem. Phys. 102:8255-63

47. Schoofs GR, Arumainayagam CR, McMaster MC, Madix RJ. 1989. Dissociative chemisorption of methane on $\operatorname{Pt}(111)$. Surf. Sci. 215:1-28

48. Hayden BE, Lamont CLA. 1989. Coupled translational-vibrational activation in dissociative hydrogen adsorption on $\mathrm{Cu}(110)$. Phys. Rev. Lett. 63:1823-25

49. Greg OS. 2002. Gas surface interactions studied with state-prepared molecules. Rep. Prog. Phys. 65:1165

50. Wight AC, Miller RE. 1998. Rainbow scattering of methane from LiF(100): probing the corrugation and anisotropy of the gas-surface potential. F. Chem. Phys. 109:1976-82

51. Chadwick H, Hundt PM, van Reijzen ME, Yoder BL, Beck RD. 2014. Quantum state specific reactant preparation in a molecular beam by rapid adiabatic passage. 7. Chem. Phys. 140:034321

52. Hundt PM, van Reijzen ME, Ueta H, Beck RD. 2014. Vibrational activation of methane chemisorption: the role of symmetry. 7. Phys. Chem. Lett. 5:1963-67

53. Maroni P, Papageorgopoulos D, Ruf A, Beck RD, Rizzo TR. 2006. Efficient stimulated Raman pumping for quantum state resolved surface reactivity measurements. Rev. Sci. Instrum. 77:054103

54. Hamilton CE, Kinsey JL, Field RW. 1986. Stimulated emission pumping: new methods in spectroscopy and molecular dynamics. Annu. Rev. Phys. Chem. 37:493-524

55. Vickerman JC, Gilmore IS, eds. 2009. Surface Analysis: The Principal Techniques. Chichester, UK: Wiley

56. Johnson AD, Daley SP, Utz AL, Ceyer ST. 1992. The chemistry of bulk hydrogen: reaction of hydrogen embedded in nickel with adsorbed $\mathrm{CH}_{3}$. Science 257:223-25

57. Fairbrother DH, Peng XD, Viswanathan R, Stair PC, Trenary M, Fan J. 1993. Carbon-carbon coupling of methyl groups on $\mathrm{Pt}(111)$. Surf. Sci. 285:L455-60

58. Fairbrother DH, Peng XD, Trenary M, Stair PC. 1995. Surface chemistry of methyl groups adsorbed on $\operatorname{Pt}(111)$. 7. Chem. Soc. Faraday Trans. 91:3619-25

59. Bisson R, Dang TT, Sacchi M, Beck RD. 2008. Vibrational activation in direct and precursor-mediated chemisorption of $\mathrm{SiH}_{4}$ on $\mathrm{Si}(100)$. F. Chem. Phys. 129:081103

60. Westermann J, Nienhaus H, Mönch W. 1994. Oxidation stages of clean and H-terminated Si(001) surfaces at room temperature. Surf. Sci. 311:101-6

61. Raval R. 1995. Probing the nature of molecular chemisorption using RAIRS. Surf. Sci. 331-33 (Part A): $1-10$

62. Juurlink LBF, McCabe PR, Smith RR, DiCologero CL, Utz AL. 1999. Eigenstate-resolved studies of gas-surface reactivity: $\mathrm{CH}_{4}\left(\nu_{3}\right)$ dissociation on Ni(100). Phys. Rev. Lett. 83:868-71

63. Higgins J, Conjusteau A, Scoles G, Bernasek SL. 2001. State selective vibrational (2v $\left.v_{3}\right)$ activation of the chemisorption of methane on Pt (111). F. Chem. Phys. 114:5277-83

64. Schmid MP, Maroni P, Beck RD, Rizzo TR. 2002. Surface reactivity of highly vibrationally excited molecules prepared by pulsed laser excitation: $\mathrm{CH}_{4}\left(2 v_{3}\right)$ on $\mathrm{Ni}(100)$. F. Chem. Phys. 117:8603-6

65. Beck RD, Maroni P, Papageorgopoulos DC, Dang TT, Schmid MP, Rizzo TR. 2003. Vibrational mode-specific reaction of methane on a nickel surface. Science 302:98-100

66. Bisson R, Sacchi M, Beck RD. 2010. Mode-specific reactivity of $\mathrm{CH}_{4}$ on $\mathrm{Pt}(110)-(1 \times 2)$ : the concerted role of stretch and bend excitation. Phys. Rev. B 82:121404

67. Bisson R, Sacchi M, Dang TT, Yoder B, Maroni P, Beck RD. 2007. State-resolved reactivity of $\mathrm{CH}_{4}\left(2 v_{3}\right)$ on $\mathrm{Pt}(111)$ and $\mathrm{Ni}(111)$ : effects of barrier height and transition state location. F. Phys. Chem. A 111:1267983 
68. Juurlink LBF, Smith RR, Killelea DR, Utz AL. 2005. Comparative study of C-H stretch and bend vibrations in methane activation on $\mathrm{Ni}(100)$ and $\mathrm{Ni}(111)$. Phys. Rev. Lett. 94:208303

69. Smith RR, Killelea DR, Del Sesto DF, Utz AL. 2004. Preference for vibrational over translational energy in a gas-surface reaction. Science 304:992-95

70. Chen N, Huang Y, Utz AL. 2013. State-resolved reactivity of methane $\left(v_{2}+v_{4}\right)$ on Ni(111). F. Phys. Chem. A 117:6250-55

71. Maroni P, Papageorgopoulos DC, Sacchi M, Dang TT, Beck RD, Rizzo TR. 2005. State-resolved gas-surface reactivity of methane in the symmetric C-H stretch vibration on Ni(100). Phys. Rev. Lett. 94:246104

72. Ueta H, Chen L, Beck RD, Colon-Diaz I, Jackson B. 2013. Quantum state-resolved $\mathrm{CH}_{4}$ dissociation on $\mathrm{Pt}(111)$ : coverage dependent barrier heights from experiment and density functional theory. Phys. Chem. Chem. Phys. 15:20526-35

73. Higgins J, Conjusteau A, Scoles G, Bernasek SL. 2001. State selective vibrational $2 v_{3}$ activation of the chemisorption of methane on Pt (111). F. Chem. Phys. 114:5277-83

74. Dombrowski E, Peterson E, Del Sesto D, Utz AL. 2015. Precursor-mediated reactivity of vibrationally hot molecules: methane activation on $\operatorname{Ir}(111)$. Catal. Today 244:10-18

75. Abram I, de Martino A, Frey R. 1982. Higher excited vibrational states of polyatomic molecules. F. Chem. Phys. 76:5727-38

76. Killelea DR, Utz AL. 2013. On the origin of mode- and bond-selectivity in vibrationally mediated reactions on surfaces. Phys. Chem. Chem. Phys. 15:20545-54

77. Donald SB, Harrison I. 2012. Dynamically biased RRKM model of activated gas-surface reactivity: vibrational efficacy and rotation as a spectator in the dissociative chemisorption of $\mathrm{CH}_{4}$ on $\mathrm{Pt}(111)$. Phys. Chem. Chem. Phys. 14:1784-95

78. Donald SB, Navin JK, Harrison I. 2013. Methane dissociative chemisorption and detailed balance on Pt(111): dynamical constraints and the modest influence of tunneling. F. Chem. Phys. 139:214707

79. Ukraintsev VA, Harrison I. 1994. A statistical model for activated dissociative adsorption: application to methane dissociation on $\operatorname{Pt}(111)$. F. Chem. Phys. 101:1564-81

80. DeWitt KM, Valadez L, Abbott HL, Kolasinski KW, Harrison I. 2006. Using effusive molecular beams and microcanonical unimolecular rate theory to characterize $\mathrm{CH}_{4}$ dissociation on $\operatorname{Pt}(111)$. F. Phys. Chem. B 110:6705-13

81. Killelea DR, Campbell VL, Shuman NS, Utz AL. 2008. Bond-selective control of a heterogeneously catalyzed reaction. Science 319:790-93

82. Chen L, Ueta H, Bisson R, Beck RD. 2012. Vibrationally bond-selected chemisorption of methane isotopologues on $\mathrm{Pt}(111)$ studied by reflection absorption infrared spectroscopy. Faraday Discuss. 157:28595

83. Hundt PM, Ueta H, van Reijzen ME, Jiang B, Guo H, Beck RD. 2015. Bond-selective and mode-specific dissociation of $\mathrm{CH}_{3} \mathrm{D}$ and $\mathrm{CH}_{2} \mathrm{D}_{2}$ on $\mathrm{Pt}(111)$. F. Phys. Chem. A 119:12442-48

84. Killelea DR, Campbell VL, Shuman NS, Utz AL. 2008. Isotope-selective chemical vapor deposition via vibrational activation. 7. Phys. Chem. C 112:9822-27

85. Juurlink LBF, Smith RR, Utz AL. 2000. Controlling surface chemistry with light: spatially resolved deposition of rovibrational-state-selected molecules. F. Phys. Chem. B 104:3327-36

86. Juurlink LBF, Smith RR, Utz AL. 2000. The role of rotational excitation in the activated dissociative chemisorption of vibrationally excited methane on Ni(100). Faraday Discuss. 117:147-60

87. Yoder BL, Bisson R, Beck RD. 2010. Steric effects in the chemisorption of vibrationally excited methane on Ni(100). Science 329:553-56

88. Yoder BL, Bisson R, Hundt PM, Beck RD. 2011. Alignment dependent chemisorption of vibrationally excited $\mathrm{CH}_{4}\left(v_{3}\right)$ on $\mathrm{Ni}(100), \mathrm{Ni}(110)$, and $\mathrm{Ni}(111)$. 7. Chem. Phys. 135:224703

89. Jiang B, Guo H. 2016. Origin of steric effects in methane dissociative chemisorption. F. Phys. Chem. C 120:8220-26

90. Nave S, Tiwari AK, Jackson B. 2010. Methane dissociation and adsorption on Ni(111), Pt(111), Ni(100), $\operatorname{Pt}(100)$, and $\operatorname{Pt}(110)-(1 \times 2)$ : energetic study. F. Chem. Phys. 132:054705

91. Bisson R, Sacchi M, Beck RD. 2010. State-resolved reactivity of $\mathrm{CH}_{4}$ on $\mathrm{Pt}(110)-(1 \times 2)$ : the role of surface orientation and impact site. F. Chem. Phys. 132:094702 
92. Killelea DR, Campbell VL, Shuman NS, Smith RR, Utz AL. 2009. Surface temperature dependence of methane activation on Ni(111). F. Phys. Chem. C 113:20618-22

93. Campbell VL, Chen N, Guo H, Jackson B, Utz AL. 2015. Substrate vibrations as promoters of chemical reactivity on metal surfaces. F. Phys. Chem. A 119:12434-41

94. Tiwari AK, Nave S, Jackson B. 2010. The temperature dependence of methane dissociation on Ni(111) and $\operatorname{Pt}(111)$ : mixed quantum-classical studies of the lattice response. $\mathcal{F}$. Chem. Phys. 132:134702

95. Jackson B, Nave S. 2013. The dissociative chemisorption of methane on Ni(111): the effects of molecular vibration and lattice motion. F. Chem. Phys. 138:174705-11

96. Walker AV, King DA. 1999. Dynamics of the dissociative adsorption of methane on $\operatorname{Pt}\{110\}(1 \times 2)$. Phys. Rev. Lett. 82:5156-59

97. Nave S, Jackson B. 2009. Methane dissociation on Ni(111) and $\mathrm{Pt}(111)$ : energetic and dynamical studies. 7. Chem. Phys. 130:054701

98. Henkelman G, Jónsson H. 2001. Theoretical calculations of dissociative adsorption of $\mathrm{CH}_{4}$ on an $\operatorname{Ir}(111)$ Surface. Phys. Rev. Lett. 86:664-67

99. Guo H, Jiang B. 2014. The sudden vector projection model for reactivity: mode specificity and bond selectivity made simple. Acc. Chem. Res. 47:3679-85

100. Jiang B, Yang M, Xie D, Guo H. 2016. Quantum dynamics of polyatomic dissociative chemisorption on transition metal surfaces: mode specificity and bond selectivity. Chem. Soc. Rev. 45:3621-40

101. Michelsen HA, Rettner CT, Auerbach DJ, Zare RN. 1993. Effect of rotation on the translational and vibrational energy dependence of the dissociative adsorption of $\mathrm{D}_{2}$ on $\mathrm{Cu}(111)$. F. Chem. Phys. 98:8294307

102. Michelsen HA, Rettner CT, Auerbach DJ. 1992. State-specific dynamics of $\mathrm{D}_{2}$ desorption from Cu(111): the role of molecular rotational motion in activated adsorption-desorption dynamics. Phys. Rev. Lett. 69:2678-81

103. Rettner CT, Auerbach DJ, Michelsen HA. 1992. Role of vibrational and translational energy in the activated dissociative adsorption of $\mathrm{D}_{2}$ on $\mathrm{Cu}(111)$. Phys. Rev. Lett. 68:1164-67

104. Hou H, Gulding SJ, Rettner CT, Wodtke AM, Auerbach DJ. 1997. The stereodynamics of a gas-surface reaction. Science 277:80-82

105. Gulding SJ, Wodtke AM, Hou H, Rettner CT, Michelsen HA, Auerbach DJ. 1996. Alignment of $\mathrm{D}_{2}(v, J)$ desorbed from $\mathrm{Cu}(111)$ : low sensitivity of activated dissociative chemisorption to approach geometry. $\mathcal{F}$. Chem. Phys. 105:9702-5

106. Rettner CT, Michelsen HA, Auerbach DJ, Mullins CB. 1991. Dynamics of recombinative desorption: angular distributions of $\mathrm{H}_{2}, \mathrm{HD}$, and $\mathrm{D}_{2}$ desorbing from $\mathrm{Cu}(111)$. F. Chem. Phys. 94:7499-501

107. Rettner CT, Michelsen HA, Auerbach DJ. 1995. Quantum-state-specific dynamics of the dissociative adsorption and associative desorption of $\mathrm{H}_{2}$ at a $\mathrm{Cu}(111)$ surface. 7. Chem. Phys. 102:4625-41

108. Kubiak GD, Sitz GO, Zare RN. 1985. Recombinative desorption dynamics: molecular hydrogen from $\mathrm{Cu}(110)$ and $\mathrm{Cu}(111)$. F. Chem. Phys. 83:2538-51

109. Rettner CT, Michelsen HA, Auerbach DJ. 1993. Determination of quantum-state-specific gas-surface energy transfer and adsorption probabilities as a function of kinetic energy. Chem. Phys. 175:157-69

110. Murphy MJ, Hodgson A. 1998. Adsorption and desorption dynamics of $\mathrm{H}_{2}$ and $\mathrm{D}_{2}$ on $\mathrm{Cu}(111)$ : the role of surface temperature and evidence for corrugation of the dissociation barrier. 7 . Chem. Phys. 108:4199-211

111. Kroes G-J, Diaz C. 2016. Quantum and classical dynamics of reactive scattering of $\mathrm{H}_{2}$ from metal surfaces. Chem. Soc. Rev. 45:3658-700

112. Gostein M, Sitz GO. 1997. Rotational state-resolved sticking coefficients for $\mathrm{H}_{2}$ on $\mathrm{Pd}(111)$ : testing dynamical steering in dissociative adsorption. F. Chem. Phys. 106:7378-90

113. Rettner CT, Auerbach DJ. 1996. Search for oscillations in the translational energy dependence of the dissociation of $\mathrm{H}_{2}$ on $\mathrm{Pd}(100)$. Chem. Phys. Lett. 253:236-40

114. Wetzig D, Dopheide R, Rutkowski M, David R, Zacharias H. 1996. Rotational alignment in associative desorption of $\mathrm{D}_{2}\left(v^{\prime \prime}=0\right.$ and 1) from $\mathrm{Pd}(100)$. Phys. Rev. Lett. 76:463-66

115. Cottrell C, Carter RN, Nesbitt A, Samson P, Hodgson A. 1997. Vibrational state dependence of $D_{2}$ dissociation on $\operatorname{Ag}(111)$. F. Chem. Phys. 106:4714-22 
116. Murphy MJ, Hodgson A. 1997. Role of surface thermal motion in the dissociative chemisorption and recombinative desorption of $\mathrm{D}_{2}$ on $\mathrm{Ag}(111)$. Phys. Rev. Lett. 78:4458-61

117. Murphy MJ, Hodgson A. 1997. Translational energy release in the recombinative desorption of $\mathrm{H}_{2}$ from Ag(111). Surf. Sci. 390:29-34

118. Kolasinski KW, Shane SF, Zare RN. 1991. Probing the dynamics of hydrogen recombination on Si(100). 7. Chem. Phys. 95:5482-85

119. Kolasinski KW, Shane SF, Zare RN. 1992. Internal-state distribution of recombinative hydrogen desorption from $\mathrm{Si}(100)$. 7. Chem. Phys. 96:3995-4006

120. Shane SF, Kolasinski KW, Zare RN. 1992. Recombinative desorption of $\mathrm{H}_{2}$ on $\mathrm{Si}(100)-(2 \times 1)$ and Si(111)-(7×7): comparison of internal state distributions. F. Chem. Phys. 97:1520-30

121. Shane SF, Kolasinski KW, Zare RN. 1992. Internal-state distributions of $\mathrm{H}_{2}$ desorbed from mono- and dihydride species on $\mathrm{Si}(100)$. 7. Chem. Phys. 97:3704-9

122. Dürr M, Höfer U. 2004. Molecular beam investigation of hydrogen dissociation on $\mathrm{Si}(001)$ and $\mathrm{Si}(111)$ surfaces. F. Chem. Phys. 121:8058-67

123. Bisson R, Dang TT, Sacchi M, Beck RD. 2007. Cavity ring-down spectroscopy of jet-cooled silane isotopologues in the Si-H stretch overtone region. F. Chem. Phys. 127:244301

124. Hundt PM, Jiang B, van Reijzen ME, Guo H, Beck RD. 2014. Vibrationally promoted dissociation of water on $\mathrm{Ni}(111)$. Science 344:504-7

125. Liu K. 2016. Vibrational control of bimolecular reactions with methane by mode, bond, and stereo selectivity. Annu. Rev. Phys. Chem. 67:91-111

126. Sinha A, Hsiao MC, Crim FF. 1991. Controlling bimolecular reactions: mode and bond selected reaction of water with hydrogen atoms. F. Chem. Phys. 94:4928-35

127. Bronikowski MJ, Simpson WR, Girard B, Zare RN. 1991. Bond-specific chemistry: OD:OH product ratios for the reactions $\mathrm{H}+\mathrm{HOD}(100)$ and $\mathrm{H}+\mathrm{HOD}(001)$. F. Chem. Phys. 95:8647-48

128. Kavulak DF, Abbott HL, Harrison I. 2005. Nonequilibrium activated dissociative chemisorption: $\mathrm{SiH}_{4}$ on $\mathrm{Si}(100)$. F. Phys. Chem. B 109:685-88

129. Halonen L, Bernasek SL, Nesbitt DJ. 2001. Reactivity of vibrationally excited methane on nickel surfaces. 7. Chem. Phys. 115:5611-19

130. Guo H, Jackson B. 2015. Mode- and bond-selective chemistry on metal surfaces: the dissociative chemisorption of $\mathrm{CHD}_{3}$ on $\mathrm{Ni}(111)$. F. Phys. Chem. C 119:14769-79

131. Nave S, Jackson B. 2010. Vibrational mode-selective chemistry: methane dissociation on $\mathrm{Ni}(100)$. Phys. Rev. B 81:233408

132. Jackson B, Nave S. 2011. The dissociative chemisorption of methane on $\mathrm{Ni}(100)$ : reaction path description of mode-selective chemistry. F. Chem. Phys. 135:114701-12

133. Guo H, Jackson B. 2016. Mode-selective chemistry on metal surfaces: the dissociative chemisorption of $\mathrm{CH}_{4}$ on $\mathrm{Pt}(111)$. 7. Chem. Phys. 144:184709

134. Farjamnia A, Jackson B. 2015. The dissociative chemisorption of water on $\mathrm{Ni}(111)$ : mode- and bondselective chemistry on metal surfaces. F. Chem. Phys. 142:234705

135. Polanyi JC. 1972. Concepts in reaction dynamics. Acc. Chem. Res. 5:161-68

136. Jiang B, Guo H. 2013. Mode and bond selectivities in methane dissociative chemisorption: quasi-classical trajectory studies on twelve-dimensional potential energy surface. 7. Phys. Chem. C 117:16127-35

137. Jiang B, Guo H. 2014. Prediction of mode specificity, bond selectivity, normal scaling, and surface lattice effects in water dissociative chemisorption on several metal surfaces using the sudden vector projection model. 7. Phys. Chem. C 118:26851-58

138. Jiang B, Guo H. 2015. Dynamics of water dissociative chemisorption on Ni(111): effects of impact sites and incident angles. Phys. Rev. Lett. 114:166101

139. Jackson B, Nattino F, Kroes G-J. 2014. Dissociative chemisorption of methane on metal surfaces: tests of dynamical assumptions using quantum models and ab initio molecular dynamics. F. Chem. Phys. 141:054102

140. Nattino F, Díaz C, Jackson B, Kroes G-J. 2012. Effect of surface motion on the rotational quadrupole alignment parameter of $\mathrm{D}_{2}$ reacting on $\mathrm{Cu}(111)$. Phys. Rev. Lett. 108:236104 
141. Nattino F, Ueta H, Chadwick H, van Reijzen ME, Beck RD, et al. 2014. Ab initio molecular dynamics calculations versus quantum-state-resolved experiments on $\mathrm{CHD}_{3}+\mathrm{Pt}(111)$ : new insights into a prototypical gas-surface reaction. 7. Phys. Chem. Lett. 5:1294-99

142. Fuchsel G, Thomas PS, den Uyl J, Ozturk Y, Nattino F, et al. 2016. Rotational effects on the dissociation dynamics of $\mathrm{CHD}_{3}$ on $\mathrm{Pt}(111)$. Phys. Chem. Chem. Phys. 18:8174-85

143. Nattino F, Migliorini D, Bonfanti M, Kroes G-J. 2016. Methane dissociation on Pt(111): searching for a specific reaction parameter density functional. 7. Chem. Phys. 144:044702

144. Nattino F, Migliorini D, Kroes G-J, Dombrowski E, High EA, et al. 2016. Chemically accurate simulation of a polyatomic molecule-metal surface reaction. 7. Phys. Chem. Lett. 7:2402-6

145. Shirhatti PR, Geweke J, Steinsiek C, Bartels C, Rahinov I, et al. 2016. Activated dissociation of $\mathrm{HCl}$ on $\mathrm{Au}(111)$. 7. Phys. Chem. Lett. 7:1346-50

146. Liu T, Fu B, Zhang DH. 2013. Six-dimensional quantum dynamics study for the dissociative adsorption of $\mathrm{HCl}$ on $\mathrm{Au}(111)$ surface. 7. Chem. Phys. 139:184705

147. Schindler B, Diesing D, Hasselbrink E. 2011. Electronic excitations induced by hydrogen surface chemical reactions on gold. F. Chem. Phys. 134:034705

148. Schindler B, Diesing D, Hasselbrink E. 2013. Electronically nonadiabatic processes in the interaction of $\mathrm{H}$ with a Au surface revealed using MIM junctions: the temperature dependence. 7 . Phys. Chem. C 117:6337-45

149. Diesing D, Hasselbrink E. 2016. Chemical energy dissipation at surfaces under UHV and high pressure conditions studied using metal-insulator-metal and similar devices. Chem. Soc. Rev. 45:3747-55 
Annual Review of Physical Chemistry

\section{Contents}

Molecules at Solid Surfaces: A Personal Reminiscence Gerhard Ertl

From 50 Years Ago, the Birth of Modern Liquid-State Science David Chandler

Quantum State-Resolved Studies of Chemisorption Reactions Helen Chadwick and Rainer D. Beck

Molecular Photofragmentation Dynamics in the Gas and Condensed Phases Michael N.R. Ashfold, Daniel Murdock, and Thomas A.A. Oliver ....

Coherent Light Sources at the Nanoscale Ankun Yang, Danqing Wang, Weijia Wang, and Teri W. Odom

Progress Toward a Molecular Mechanism of Water Oxidation in Photosystem II

David 7. Vinyard and Gary W. Brudvig

Computer Simulations of Intrinsically Disordered Proteins Song-Ho Chong, Pratbit Chatterjee, and Sibyun Ham

QM/MM Geometry Optimization on Extensive Free-Energy Surfaces for Examination of Enzymatic Reactions and Design of Novel Functional Properties of Proteins Shigebiko Hayashi, Yoshibiro Ucbida, Taisuke Hasegawa, Masabiro Higashi, Takabiro Kosugi, and Motoshi Kamiya

Development of New Density Functional Approximations

Neil Qiang Su and Xin Xu

Criegee Intermediates: What Direct Production and Detection Can

Teach Us About Reactions of Carbonyl Oxides

Craig A. Taatjes

Water Oxidation Mechanisms of Metal Oxide Catalysts by Vibrational Spectroscopy of Transient Intermediates Miao Zhang and Heinz Frei

Reaction Mechanisms on Multiwell Potential Energy Surfaces in Combustion (and Atmospheric) Chemistry

David L. Osborn 
Phospholipid Bilayers: Stability and Encapsulation of Nanoparticles

Elnaz Alipour, Duncan Halverson, Samantha McWhirter, and Gilbert C. Walker ... 261

Ice Surfaces

Mary fane Shultz

Metal-Free Motifs for Solar Fuel Applications

Stefan Ilic, Marija R. Zoric, Usha Pandey Kadel, Yunjing Huang,

and Ksenija D. Glusac

Ion-Molecule Reaction Dynamics

Jennifer Meyer and Roland Wester....

Computational Analysis of Vibrational Sum Frequency Generation Spectroscopy

Tatsuya Ishiyama and Akibiro Morita .................................... 355

Hot Charge Carrier Transmission from Plasmonic Nanostructures

Phillip Christopher and Martin Moskovits

Calculating Natural Optical Activity of Molecules from First Principles Monika Srebro-Hooper and Fochen Autschbach....

Random-Phase Approximation Methods

Guo P. Chen, Vamsee K. Voora, Mattbew M. Agee, Sree Ganesh Balasubramani, and Filipp Furche

The Hydrated Electron

Jobn M. Herbert and Marc P. Coons

Ultrafast X-Ray Crystallography and Liquidography

Hosung Ki, Key Young Oang, Jeongho Kim, and Hyotcherl Ibee ...

Roaming: A Phase Space Perspective

Frédéric A.L. Mauguière, Peter Collins, Zeb C. Kramer, Barry K. Carpenter,

Gregory S. Ezra, Stavros C. Farantos, and Stephen Wiggins

Extending Quantum Chemistry of Bound States to Electronic Resonances

Thomas-C. Jagau, Ksenia B. Bravaya, and Anna I. Krylov

The Importance of Being Inconsistent

Adam Wasserman, Jonathan Nafziger, Kaili Fiang, Min-Cheol Kim, Eunji Sim, and Kieron Burke

\section{Indexes}

Cumulative Index of Contributing Authors, Volumes 64-68

Cumulative Index of Article Titles, Volumes 64-68

\section{Errata}

An online log of corrections to Annual Review of Physical Chemistry articles may be found at http://www.annualreviews.org/errata/physchem 